\title{
CAMBIOS TECNOLÓGICOS Y PROYECTOS ECONÓMICOS EN LAS FUERZAS ARMADAS DE CHILE, 1860-1930**
}

En el presente artículo se analizan las relaciones entre cambios tecnológicos y proyectos económicos que experimentaron los militares chilenos entre 1860 y 1930, y que conformaron algunas corrientes a favor de la industria, del nacionalismo económico y de la intervención del Estado en sectores que se consideraron como estratégicos, todo lo cual adquirió notoriedad en la década de 1920. Sin embargo, dichas corrientes no lograron consenso y fueron combatidas por los empresarios y la tecnocracia. Se explora una explicación que considera los límites impuestos a los militares por los civiles en el control del Estado y de la economía, la incompleta modernización tecnológica, las concepciones contrapuestas entre la Armada y el Ejército sobre sus proveedores de armas, además de que los posibles escenarios de guerra de Chile no serían de gran escala. Todo ello descartó una posible alianza de intereses militares, empresariales y tecnocráticos para conformar un complejo militar industrial de mayor alcance.

Palabras clave: Fuerzas Armadas, tecnología, historia económica, industrialización.

This article analyses the relationship between technological changes and economic projects experienced by Chilean military institutions between 1860 and 1930 . These changes were part of industrializing streams that emerged as a result of economic nationalism and State interventions in strategic areas since the 1920s. However, these measures did not have an institutional consensus and were opposed by businessmen and technocrats. The article considers different aspects including the limits imposed to military institutions by civilians in terms of State control and economic management as well as the incomplete technological modernization and different views of the Army and Navy over weapon providers and the kind of potential war scenarios. All of these made the alliance between military,

* Centro de Investigaciones Interdisciplinarias en Ciencias y Humanidades (CEIICH), Universidad Nacional Autónoma de México. Investigador del Sistema Nacional de Investigadores de México. Correo electrónico: guillermo.guajardo@servidor.unam.mx

** Este artículo es parte de la investigación que se lleva a cabo en el seminario Historia económica de la inserción internacional de América Latina: el contexto regional y las experiencias comparadas de Chile y México y del proyecto Innovación, Empresa y Estado en México y América Latina: Teorías, metodologías y prácticas interdisciplinarias del Programa de Investigación Ciencia y Tecnología del CEIICH. Una parte de este trabajo contó con apoyo del proyecto El taller ferroviario y los orígenes de la industria en México y Chile, 1850-1950: un estudio histórico de la transferencia tecnológica y de la innovación, financiado por el Fondo Institucional / Ciencia Básica 2006 Clave 52635 del Consejo Nacional de Ciencia y Tecnología de México. 
businessmen and technocrat interests to create a military industrial facility impossible.

Key words: Armed forces, technology, economic history, industrialization.

Fecha de recepción: abril 2008

Fecha de aceptación: septiembre 2008

\section{INTRODUCCIÓN}

Desde mediados del siglo XIX y hasta la década de 1930, la venta y transferencia de tecnologías militares europeas difundió la mecanización de la guerra, a la vez que contribuyó a modernizar los nacientes estados del Tercer Mundo. En un mercado internacional caracterizado por débiles regulaciones políticas y comerciales para la venta de armamento, países con fuertes disputas fronterizas, como Argentina, Brasil, Chile y Perú, compraron acorazados, cañones e instrucción que, a su vez, demandaron nuevos conocimientos, capacidades laborales y la construcción de arsenales y talleres, lo que cambió tanto la concepción de la guerra como las ideas y capacidades militares ${ }^{1}$.

Al respecto, el interés del presente artículo son las relaciones entre los cambios tecnológicos introducidos por las nuevas armas y los proyectos de los militares chilenos para establecer industrias y participar en sectores que consideraron estratégicos, como los ferrocarriles, entre las décadas de 1860 y 1930. Al calor de esas interacciones se conformaron algunas corrientes de nacionalismo económico e industrialismo, que encontraron límites materiales y políticos para su realización; por lo demás, los mismos militares no lograron generar una alianza de intereses estatales y empresariales capaz de establecer un posible complejo militar-industrial nacional. Los esfuerzos que hemos detectado en esa dirección fueron dispersos y adquirieron mayor ritmo y frecuencia solo desde la Primera Guerra Mundial, para expresarse más nítidamente en la década de 1920. Para este punto, se explora una explicación que considera cuatro aspectos.

El primero fueron los límites impuestos a esos proyectos por la supremacía civil en el control del Estado y de la economía. El segundo fue la incompleta modernización tecnológica, que privilegió la compra de armas y descuidó la tecnificación del personal. El tercero se refiere a las fuentes internacionales de abastecimiento de armas: la Armada, desde la década de 1870, adquirió un moderno poder de combate gracias a una fluida relación comercial con Gran Bretaña, a diferencia del Ejército,

1 Barton C. Hacker, "The Machines of War: Western Military Technology 1850-2000", en History and Technology, Vol. 21, No 3, London, 2005, 255-300; David Arnold, "Europe, Technology, and Colonialism in the 20th Century", en History and Technology, Vol. 21, $\mathrm{N}^{\circ}$ 1, London, 2005, 85106; Alex Roland, The Military-Industrial Complex. Washington, D.C., American Historical Association, 2001; David Ralston, Importing the European Army: The Introduction of European Military Techniques and Institutions into the Extra-European World, 1600-1914, Chicago, University of Chicago Press, 1990. 
que desde la década de 1880 adoptó como modelo a Alemania. Esto creó tendencias contrapuestas: la Armada fue más tecnificada e industrial pero también más liberal e internacional, mientras que el Ejército fue poco tecnificado y más proclive a posturas industrialistas y nacionalistas. El cuarto, y último, fue la percepción de que Chile no necesitaría estar preparado para escenarios de guerra de gran escala, sino para operaciones que demandarían logística y movilidad, así como crédito y abastecimientos seguros desde el exterior. Los proyectos que llegaron a materializarse estaban enfocados a establecer una capacidad local de mantenimiento, pero no un complejo que aglutinara los intereses militares con los empresariales y tecnocráticos.

El marco temporal en que se dieron esos fenómenos se caracterizó por la existencia de guerras internacionales y la lenta incursión de los militares en política a partir de la década de 1890, así como por una temprana e importante carrera de armamentos navales entre 1884 y 1902 . Todo esto en una economía dinámicamente abierta al exterior, pero carente de una industria pesada significativa y de capital humano calificado, que experimentó crecientes niveles de conflictividad social y de pobreza.

Estos aspectos no han sido bien tratados por la historiografía militar, económica y de la tecnología en Chile y, en general del Tercer Mundo, en particular los fenómenos asociados a la temprana capacidad de producción de armas. Ese tema fue indicado por Gábor Ágoston, al estudiar la producción de pólvora y artillería en el Imperio Otomano, durante los siglos XVI y XVII; y también Kaushik Roy, quien en su trabajo sobre las Ordnance Factories de la India británica antes de 1913 determinó que dichos establecimientos, que abastecían de municiones, armas y accesorios al ejército colonial, no pudieron desarrollar su potencial por las restricciones impuestas por la metrópoli a la producción de armas sofisticadas en las colonias $^{2}$. Situaciones similares se pueden encontrar en América Latina, a pesar de lo cual la historia industrial de los militares ha sido una vertiente de estudio marginal, ya que la atención ha estado centrada en temas como la autonomía corporati$\mathrm{va}^{3}$, la profesionalización y formación de los oficiales ${ }^{4}$ y la subordinación de los militares a los intereses de las potencias internacionales y de las élites locales ${ }^{5}$.

2 Gábor Ágoston, Guns for the Sultan: Military Power and the Weapons in the Ottoman Empire, Cambridge, Cambridge University Press, 2005; Kaushik Roy, "Equipping Leviathan: Ordnance Factories of British India, 1859-1913", en War in History, Vol. 10, N 4, London, 2003, 398-423.

3 Loris Zanatta, Del Estado liberal a la nación católica. Iglesia y Ejército en los orígenes del peronismo, 1930-1943, Bernal, Prov. de Buenos Aires, Universidad Nacional de Quilmes, 1996; Riccardo Forte, "Génesis del nacionalismo militar. Participación política y orientación ideológica de las fuerzas armadas argentinas al comienzo del siglo XIX”, en Signos Históricos, N ${ }^{\circ}$ 2, Vol. I, México, 1999, 103-135; Stanley Hilton, "The Armed Forces and Industrialists in Modern Brazil: The Drive for Military Autonomy (1889-1954)", en Hispanic American Historical Review, Vol. 62, Durham, 1982, 629-673; Alain Rouquié, Poder militar y sociedad política en la Argentina (I), Buenos Aires, Emecé Editores, 1981 .

4 Gran parte de las preocupaciones han sido la profesionalización, conducta política de los altos oficiales, así como las relaciones entre civiles y militares, siguiendo la tradición de la clásica obra de Samuel Huntington, The Soldier and the State: The Theory and Politics of Civil-Military Relations, Cambridge, Mass, Harvard University Press, 1957.

5 Amos Perlmutter, Modern Authoritarianism, New Haven, Yale University Press, 1981; Id., The Military and Politics in Modern Times, New Haven, Yale University Press, 1977; Fernando H. Cardoso, "The Characterization of Authoritarian Regimes", en David Collier (ed.), The New Authorita- 
En el caso de Chile, el régimen militar (1973-1990) estimuló una extensa agenda de investigación sobre la actividad política de las Fuerzas Armadas y la influencia de las doctrinas tanto europeas como norteamericanas en su institucionalización ${ }^{6}$, además de haber implantado un consistente modelo de economía liberal ${ }^{7}$ y haber puesto fin al debate de casi un siglo sobre las opciones para el desarrollo del mercado interno y del papel del Estado ${ }^{8}$. Sin embargo, poco se ha avanzado en conocer la historia económica y tecnológica de este importante actor, que aclara varias pistas sobre la intervención de los militares en el Chile contemporáneo. En todo caso debe destacarse el notable trabajo de Sater y Herwig, publicado hace casi una década, que explora los aspectos de organización, logística y abastecimientos del Ejército, cuestionando los resultados en su

rianism in Latin America, New Jersey, Princeton University Press, 1979; Alain Rouquié, L'État Militaire en Amérique Latine, París, Éditions du Seuil, 1982. Brian Loveman, "Protected Democracies' and Military Guardianship: Political Transitions in Latin America 1978-1993", en Journal of Interamerican Studies and World Affairs, Vol. 36, Coral Gables, Fl., 1994, 105-189; William I. Robinson, Promoting Polyarchy: Liberalization, US Intervention and Hegemony, Cambridge, Cambridge University Press, 1996; Peter Smith, Talons of Eagle: Dynamics of U.S.-Latin American Relations, New York, Oxford University Press, 1996.

6 Gregory Weeks, The Military and Politics in Postauthoritarian Chile, Tuscaloosa, University of Alabama Press, 2003; Alain Joxe, Las fuerzas armadas en el sistema político chileno, Santiago, Editorial Universitaria, 1970; Patricio Quiroga, "Fuerzas armadas, sistema político y cosmovisión”, en Proposiciones, $\mathrm{N}^{\circ}$ 24, Santiago, 1994, 111-117; Luis Barros, "La profesionalización del Ejército y su conversión en un sector innovador hacia comienzos del siglo", en Estudios Sociales, N ${ }^{\circ} 73$, Santiago, 1992, 57-73; Jean-Pierre Blancpain, "L’armée chilienne et les instructeurs allemands en Amérique Latine (1885-1914)", en Revue Historique, Vol. 578, París, 1991, 347-394; Enrique Brahm García, "Del soldado romántico al soldado profesional. Revolución en el pensamiento militar chileno, 18851940", en Historia, № 25, Santiago, 1990, 5-37; Carlos Maldonado Prieto, "La Prusia de América del Sur': acerca de las relaciones militares chileno-germanas, 1927-1945", en Estudios Sociales, N ${ }^{\circ} 73$, Santiago, 1992, 75-102; Frederick Nunn, Yesterday's Soldiers. European Military Professionalism in South America, 1890-1940, Lincoln, University of Nebraska Press, 1983; Id., "Emil Körner and the Prussianization of the Chilean Army: Origins, Patterns, and Consequences, 1885-1920", en Hispanic American Historical Review, Vol. 50, No 2, Duke, 1970, 300-322; Patricio Quiroga, "El prusianismo en las fuerzas armadas chilenas. Un esquema de evolución histórico, 1885-1918", en Revista Andes, $\mathrm{N}^{\circ}$ 1, Santiago, 1984, 89-119.

7 Âlvaro García y John Wells, "Chile: a Laboratory for Failed Experiments in Capitalist Political Economy", en Cambridge Journal of Economics, Vol. 7, N 3/4, Oxford, 1983, 287-304; Carlos Huneeus, "Technocrats and Politicians in an Authoritarian Regime. The 'ODEPLAN Boys' and the 'Gremialist' in Pinochet's Chile", en Journal of Latin American Studies, Vol. 32, No 2, Cambridge, 2000, 461-501; Marcus J. Kurtz, "Chile's Neo-Liberal Revolution: Incremental Decisions and Structural Transformation, 1973-89”, en Journal of Latin American Studies, Vol. 31, No 2, Cambridge, 1999, 399-427; Eduardo Silva, The State and Capital in Chile. Business, Elites, Technocrats, and Market Economics, Boulder, CO, Westview Press, 1996; Eugenio Tironi, Autoritarismo, modernización y marginalidad. El caso de Chile, 1973-1989, Santiago, Ediciones Sur, 1990: Juan Gabriel Valdés, Pinochet's Economist: The Chicago School in Chile, New York / Cambridge, Cambridge University Press, 1995; John Markoff y Verónica Montecinos, "El irresistible ascenso de los economistas", en Desarrollo Económico, Vol. 34, N 133, Buenos Aires, 1994, 3-29.

8 Guillermo Guajardo, “¿Por qué los militares chilenos no fueron industrialistas? Una visión sobre el pensamiento económico de las Fuerzas Armadas", en Fuerzas Armadas y Sociedad, Año 16, $\mathrm{N}^{\circ}$ 1, Santiago, enero-marzo de 2001, 48-55; Guillermo Guajardo, "Desde el cuartel. La oposición civil a los proyectos económicos de los militares en Chile, c. 1860-1930", en Riccardo Forte y Guillermo Guajardo (coords.), Consenso y coacción. Estado e instrumentos de control político y social en México y América Latina (siglos XIX y XX), México, El Colegio de México - El Colegio Mexiquense, 2000, 315-350. 
capacidad operativa y la gestión de la asesoría alemana contratada en la década de $1880^{9}$.

En trabajos anteriores hemos planteado la debilidad del industrialismo entre los militares y en el presente artículo queremos plantear que, en la década de 1920, asomó un tenue industrialismo y nacionalismo económico que fue producto no solo del ambiente social, ideológico y económico, sino también de procesos internos de tecnificación y tensiones laborales. Diferimos de la interpretación que considera que la adopción del modelo alemán en el Ejército habría entregado a los militares una idolatría estatal, la cual, para la década de 1920, se habría expresado en una tendencia desarrollista-estatista, contraria al pensamiento económico liberal identificado con el capitalismo británico. Si bien es cierto que se pueden encontrar esas ideas, hay que tener en cuenta que estas se limitaron a determinados sectores y niveles dentro del Ejército y, en menor medida, de la Armada, sin llegar a articular una doctrina económico militar. A su vez, estos análisis toman a las Fuerzas Armadas como un todo, ignorando las diferencias de fondo entre los servicios, en particular el papel que tuvo la Marina de guerra en moderar las tendencias "desarrollistas-estatistas", a pesar de que era la institución más tecnificada, incluso si se la compara con otros sectores de la economía chilena.

Una prueba de esa conducta se encuentra en la época de las intervenciones militares, entre 1924 y 1932, que impulsaron la reforma del Estado y de la economía. A pesar del gran poder que tuvieron las Fuerzas Armadas, no comandaron la intervención pública y la industrialización, ni fueron parte de la alianza de empresarios y tecnócratas que dirigió el desarrollismo de las décadas posteriores. Más tarde el péndulo tomó otra dirección, el liberalismo económico, la apertura externa y la desindustrialización. Paradójicamente la alianza que desde la década de 1930 los excluyó de las decisiones del desarrollismo, a partir del decenio de 1950 tendió puentes de plata a través de ingenieros civiles, empresarios industriales y economistas de cuño neoaustriaco. Se construyó un consenso sobre un proyecto económico antidesarrollista, que impulsaron en forma radical desde 1973. Nuevamente, fue la Armada la que cumplió un papel relevante al apoyar las posturas pro liberales, repitiendo la conducta de apoyar un cambio radical y luego entregarle a la tecnocracia el control del proyecto: en la década de 1920 fue a los ingenieros civiles y en la de 1970 a los economistas neoliberales.

Los antecedentes de esa conducta han sido tratados en estas secciones. En las tres siguientes establecemos el marco de condiciones materiales, sociales e ideológicas que fueron fundamentales para su desarrollo. Luego presentamos un esquema de los fenómenos que analizamos con más detención en las once secciones siguientes. La última es de conclusiones.

9 En todo caso deben destacarse los trabajos de Sater y Herwig, así como de Brahm García, que analizan la organización, logística y abastecimientos del Ejército, cuestionando desde distintos ángulos los resultados de la asesoría alemana contratada en la década de 1880, en especial en su capacidad operativa. Enrique Brahm García, Preparados para la guerra. Pensamiento militar chileno bajo influencia alemana 1885-1930, Santiago, Ediciones Universidad Católica de Chile, 2003; William Sater y Holger H. Herwig, The Grand Illusion. The Prussianization of the Chilean Army, Lincoln, University of Nebraska Press, 1999. 


\section{EL MARCO MATERIAL Y SOCIAL}

Para aproximarnos al tema, debemos considerar las características de Chile en el período 1860 y 1930. El país, después de 1818, logró una temprana consolidación política e institucional con la supremacía civil, dimensión que se combinó con ciclos de exportación de alguna materia prima básica. De acuerdo a Díaz, Lüders y Wagner, entre 1810 y 1860 la economía chilena experimentó una transición hacia la integración internacional, expresada en el coeficiente de exportación más importación (ambos quantum) respecto del PIB, el cual pasó desde el $6 \%$ al $21 \% 10$. Desde 1830 la minería ocupó entre la mitad y dos tercios de las exportaciones del país, cifra que pasó del 76,1\% en el decenio de 1880 al 91,4\% en 1900, con lo cual para 1914 el país se había consolidado como un exitoso exportador minero ${ }^{11}$. Ello también estimuló los flujos de inversión: en 1914 del total de la inversión extranjera en la región latinoamericana, el $42 \%$ estaba en Argentina, el 15\% en México y en Chile residía el $6,5 \%{ }^{12}$.

Si bien el país era un exportador neto de materias primas, su complejidad era mucho mayor que la de un simple polo de exportación. En el plano económico, además del papel protagónico de los empresarios chilenos en la expansión minera, el Estado, desde la década de 1850, asumió un importante rol en el desarrollo de ferrocarriles y obras públicas. Entre 1854 y 1916 cerca del 30\% del presupuesto público se canalizó hacia el área de infraestructura, robusteciendo al sector público como operador de líneas férreas: en 1880 controlaba $950 \mathrm{~km}$, equivalentes al 53\% del total del país, que se elevaron a 5.807 kilómetros en 1930, con el 64\%. La mayor inversión en ferrocarriles estatales se localizó en las provincias del centro y sur del país, donde estaba la base de poder de los terratenientes ${ }^{13}$.

10 José Díaz B, Rolf Lüders y Gert Wagner, "Economía Chilena 1810-2000; producto total y sectorial; una nueva mirada", Santiago, P. Universidad Católica de Chile, Instituto de Economía, Serie Documento de Trabajo, $N^{\circ} 315,2007,47$.

11 Patricio Meller, "Una perspectiva de largo plazo del desarrollo económico chileno, 18801990", en Magnus Blomström y Patricio Meller (coords), Trayectorias divergentes. Comparación de un siglo de desarrollo económico latinoamericano y escandinavo, Santiago, CIEPLAN-Hachette, 1990,54; Luis Valenzuela, "The Cooper Smelting Company 'Urmeneta y Errázuriz' of Chile: An Economic Profile, 1860-1880", en The Americas, Vol. 53, № 2, Washington, D.C, 1996, 235-271; Victor Bulmer-Thomas, The Economic History of Latin America since Independence, Cambridge, Cambridge University Press, 1994, 48-154; Henry Kirsch, Industrial Development in a Traditional Society. The Conflict of Entrepreneurship and Modernization in Chile, Gainesville, The University Presses of Florida, 1977, 161-162, Tabla A-1; Pierre Vayssière, "La division internationale du travail et la dénationalisation du cuivre chilien (1880-1920)", en Caravelle, N ${ }^{\circ}$ 20, Toulouse, 1973, 7-29; Harold Blakemore, British Nitrates and Chilean Politics, 1886-1896: Balmaceda and North, London, University of London-The Athlone Press, 1974.

12 Bulmer-Thomas, op . cit., 104, tabla 4.3

13 Markos Mamalakis, Historical Statistics of Chile. Government Services and Public Sector an a Theory of Services, Vol. 6, Westport, Grenwood Press, 1989, 285, tabla 5.18; Robert Oppenheimer, "Chilean Transportation Development: The Railroad and Socio-Economic Change in the Central Valley, 1840-1885", Ph.D. Thesis, University of California, Los Angeles, 1976; Guillermo Guajardo, Tecnología, Estado y Ferrocarriles en Chile, 1850-1950, Madrid y México, Fundación de los Ferrocarriles Españoles - CEIICH / UNAM, 2007. 
En el plano político, si bien el sistema poco a poco empezó a dar acceso creciente a una diversidad de partidos, también permitió a los terratenientes retener su poder. Por ello, a pesar de los cambios dados desde la década de 1880 por el crecimiento del sector salitrero y de la población urbana, hacia 1900 había más senadores y diputados vinculados a la clase hacendada que en 1850; el campo hasta la década de 1960 se mantuvo conservador ${ }^{14}$. El control político del mundo rural fue hegemónico, tanto así que en la década de 1880, el embajador del emperador ruso Alejandro III en Sudamérica, Alexandr Ionin, de quien según Olga Uliánova "sería difícil sospechar de tener ideas de revolución social", señaló que en ninguna parte en América había visto tantas diferencias y tanta sumisión del bajo pueblo como en la hacienda chilena, comparable solo con la servidumbre abolida en Ru$\operatorname{sia}^{15}$. Estos elementos caracterizaron a una élite que, a juicio de Bauer, estaba constituida por "civilizados consumidores y primitivos productores" 16 .

Crecimiento y concentración del poder crearon un círculo vicioso, expresado en bajos niveles de esperanza de vida de la población: a mediados del siglo XIX esta, para un varón, no superaba los 28 años, situación que se modificó levemente hacia 1940. Para mediados del siglo XIX, de cada mil niños nacidos vivos, menos de 70 alcanzaban el año de edad y no más de la mitad alcanzaba la condición de adulto, producto de una de las tasas de mortalidad infantil más altas del mundo. En la década de 1830, en las Casas de Huérfanos la mortalidad infantil fluctuaba entre 470 y 610 por mil anual ${ }^{17}$. Para la década de 1880 las tasas de mortalidad infantil alcanzaron niveles superiores a 800 por mil anual, mientras que para 1938 eran de 236. Fue recién a partir de la década de 1960 cuando se registraron niveles inferiores a 100 por 1.000 , cifra que cayó sustancialmente desde fines de la década de $1970^{18}$.

Este escenario no fue obstáculo para movilizar sus recursos con el fin de enfrentar guerras internacionales, que expandieron en casi un tercio el territorio de la república y que tuvieron un impacto profundo sobre la economía y las Fuerzas Armadas. Clave fue la Guerra del Pacífico contra Perú y Bolivia (1879-1883), conflicto que inauguró el ciclo exportador del salitre (1880-1930) y más tarde el

14 Arnold Bauer, "Sociedad y política rural chilena en un enfoque comparativo", en Proposiciones, $\mathrm{N}^{\circ} 19$, Santiago, 1990, 254-262.

15 Olga Uliánova, "Levantamiento campesino de Lonquimay y la internacional comunista", en Estudios Públicos, $\mathrm{N}^{\circ}$ 89, Santiago, 2003,174.

16 Arnold Bauer, "Industry and the Missing Bourgeoisie: Consumption and Development in Chile, 1850-1950", en Hispanic American Historical Review, Vol. 70, № 2, Duke, 1990, 248-249.

17 Gabriel Salazar, "Ser niño 'huacho' en la historia de Chile (Siglo XIX)", en Proposiciones, N ${ }^{\circ}$ 19, Santiago, 1990, 79. María Angélica Illanes, et al., Historia del movimiento social y de la salud pública en Chile, 1885-1920, Santiago, Colectivo de Atención Primaria, 1989, 57; René Salinas, "Salud, ideología y desarrollo social en Chile, 1830-1950", en Cuadernos de Historia, No 3, Santiago, 1983, 123.

18 Salvador Allende, La realidad médico-social chilena, Santiago, Ministerio de Salubridad, Previsión y Asistencia Social, 1939, 78-79; René Salinas y Manuel Delgado, "Los hijos del vicio y del pecado: la mortalidad de los niños abandonados (1750-1930)", en Proposiciones, $\mathrm{N}^{\circ}$ 19, Santiago, 1990, 46-52; Tarsicio Castañeda, "Contexto socioeconómico y causas del descenso de la mortalidad infantil en Chile”, en Estudios Públicos, N 64, Santiago, 1984, 8-12. 
del cobre. Las provincias capturadas de Tarapacá y Antofagasta incorporaron una actividad económica que registró un crecimiento sostenido, ya que entre 1880 y 1920 la cantidad física de exportaciones de salitre creció a un ritmo de 6,1\% anual; y para 1914 estas alcanzaban cerca del 70\% del total de las exportaciones chilenas. Este artículo aportó casi el 50\% de los impuestos totales entre 1895 y 1920, recursos que permitieron incrementar el tamaño del Estado en el PIB de un 5-6\% en 1880, a $12-14 \%$ entre 1910-20; dedicar, desde la década de 1890, entre el $18 \%$ y el $33 \%$ del presupuesto nacional a la defensa y aumentar el empleo público de 3.000 plazas en 1880 a 27.000 en $1919^{19}$.

La riqueza minera fue un gran atractivo para las inversiones estadounidenses, lo que cambió el perfil del comercio exterior chileno. Poco antes de la Primera Guerra Mundial el $21 \%$ de las exportaciones iba hacia Estados Unidos y el 59\% a Gran Bretaña y Alemania, mientras que para el año de 1920, Chile elevó a 44\% los envíos a los Estados Unidos y bajó a $20 \%$ las exportaciones a Gran Bretaña. La transición desde el predominio europeo al estadounidense fue el marco para un cambio de gran magnitud, dado a partir de 1920 con la elección del presidente Arturo Alessandri Palma (1920-25 y 1932-38), que asumió reformas postergadas, a la vez que abrió un período de inestabilidad. El cobre, a partir de 1924, empezó a relevar al salitre en la tributación a las exportaciones mineras ${ }^{20}$.

También en 1924 empezaría una sucesión de intervenciones militares, con un Comité Militar, una Junta Militar y una Junta de Gobierno, que irían forzando la aprobación de leyes sociales postergadas por el régimen parlamentario; renunciaría el presidente Arturo Alessandri y se promulgaría una nueva Constitución en 1925, que separó a la Iglesia del Estado y le dio gran poder al Ejecutivo ${ }^{21}$. Todo ello dio paso a un nuevo tejido institucional. En 1925 se estableció el Banco Central de Chile como única entidad emisora de circulante, el Servicio de Minas del Estado (1925), la Caja de Crédito Agrícola (1926), la Caja de Crédito Minero (1927), la Caja de Crédito Carbonero y el Instituto de Crédito Industrial, ambos creados en $1928^{22}$. Importante fue la creación, en 1927, del Ministerio de Fomento, que elaboró los primeros planes económicos de carácter nacional guiados por ingenieros civiles y que sería el antecedente de la Corporación de Fomento de la Producción

19 Meller, op. cit., 55; Mamalakis, op. cit., 279 y 282, tabla 5.15 y 5.17.

20 Gert Wagner, "Un siglo de tributación minera: 1880-1980", Santiago, P. Universidad Católica de Chile, Instituto de Economía, Serie Documento de Trabajo, No 288, 2005, 24; Thomas F. O’Brien, "Rich Beyond the Dreams of Avarice: The Guggenheims in Chile", en Business History Review, Vol. 63, Boston, 1989, 123-124; Juan Alfonso Bravo, "Inversiones norteamericanas en Chile: 1904-1907", en Revista Mexicana de Sociología, Vol. 43, № 2, México, 1981, 775-818; Manuel Fernández, "E1 enclave salitrero y la economía chilena, 1880-1914", en Nueva Historia. Revista de historia de Chile, $\mathrm{N}^{\circ}$ 1, Londres, 1981, 2-42; Michael Monteón, Chile in the Nitrate Era. The Evolution of Economic Dependence, 1880-1930, Madison, The University of Wisconsin Press, 1982.

21 Gabriel Palma, "Chile 1914-1935: de economía exportadora a sustitutiva de importaciones", en Nueva Historia. Revista de historia de Chile, $\mathrm{N}^{\circ}$ 2, Londres, 1983, 165-192; Adolfo Ibáñez Santa María, "Los ingenieros, el Estado y la política en Chile. Del Ministerio de Fomento a la Corporación de Fomento, 1927-1939", en Historia , No 18, Santiago, 1983, 45-102; José Pablo Arellano, Políticas sociales y desarrollo. Chile 1924-1984, Santiago, CIEPLAN, 1988.

22 Palma, op. cit., 171-184. 
(CORFO), establecida en 1939 para promocionar la industria manufacturera, modernizar la agricultura y la infraestructura. Este tejido institucional dio cierto margen de maniobra para enfrentar la depresión de 1929, a la vez que estimuló la sustitución de importaciones.

\section{CONFLICTOS EXTERNOS E INESTABILIDAD INTERNA: ENTRE EL ORDEN Y LA FUERZA}

Al marco material debe sumarse la dinámica de orden y conflicto en el que se formaron las Fuerzas Armadas, habiendo ciertos momentos en que actuaron como catalizadores y aceleradores. Tales fueron la guerra contra España, a mediados de la década de 1860, la Guerra del Pacífico, la guerra civil de 1891, la carrera de armamentos navales con Argentina, entre 1884 y 1902, y la participación política entre 1924 y 1932. Se aceleraron los cambios tecnológicos a la vez que se abrieron tensiones con el mundo civil por el creciente poder que adquirieron dentro del Estado, lo cual se hizo evidente con la guerra civil de 1891, que cambió las prioridades del gasto público hacia la defensa y la infraestructura ${ }^{23}$. Un aspecto interesante de la guerra civil de 1891, fue que se libró con movilización y tácticas de una guerra internacional, empleándose armas modernas como el crucero y la detonación, del torpedo Whitehead ${ }^{24}$, lo que es un ejemplo de la radicalidad que adquirían las intervenciones militares.

A pesar de esas violencia, para autores como Samuel y Arturo Valenzuela esos actos violentos "no alteraron el que se puede ver, a la larga, como un desarrollo esencialmente lineal hacia un mayor nivel de competitividad y participación", siendo central la estabilidad y solidez del sistema de partidos políticos ${ }^{25}$. Sin embargo, para Jocelyn-Holt esa estabilidad fue aparente y el poder del Estado muy relativo, porque hasta la década de 1860 el país estuvo casi la mitad del tiempo bajo regímenes de emergencia y estallaron dos guerras civiles ${ }^{26}$. Kowalewski, al estudiar la violencia de carácter político de 34 países del Tercer Mundo, estableció que Chile registró el 11,5\% del período 1821-1985, es decir cerca de 18 años bajo condiciones de violencia política, conflictos civiles e intentos revolucionarios ${ }^{27}$. En ese sentido sí hubo violencia que adquirió larga duración (1830, 1851, 1859, 1891, 1924-32), pero lo que garantizó el control fue más bien el temprano cultivo del “orden” público, la duradera visión oligárquica de la realidad y la persistencia de

23 Monteón, Chile in the Nitrate..., op. cit., 57-119; Maurice Zeitlin, The Civil Wars in Chile (on the bourgeois revolutions that never were), Princeton, Princeton University Press, 1984, 74-75; Alfredo Jocelyn-Holt, El peso de la noche. Nuestra frágil fortaleza histórica, Santiago, PlanetaAriel, 1998, 166.

24 Carlos López Urrutia, Historia de la marina de Chile, Santiago, Editorial Andrés Bello, $1968,324$.

25 Tomás Moulian, "Chile. Las condiciones de la democracia", en Nueva Sociedad, N ${ }^{\circ} 140$, Caracas, 1995, 4; Arturo Valenzuela y Samuel Valenzuela, "Los orígenes de la democracia. Reflexiones teóricas sobre el caso de Chile”, en Estudios Públicos, No 12, Santiago, 1983, 11.

26 Jocelyn-Holt, op. cit., 24.

27 David Kowalewski, "Periphery Revolutions in World-System Perspective, 1821-1985", en Comparative Political Studies, Vol. 24, No 1, London, 1991, 95. 
sentimientos antianárquicos profundos ${ }^{28}$. Por ello, varias veces las fuerzas militares fueron desmanteladas, anulándolas como polo de poder; así ocurrió tras la victoria sobre la Confederación Perú-boliviana, en 1839, momento en que se estructuró la primera guardia nacional -bajo control civil- como contrapeso al Ejército. Tras la victoria militar sobre Perú y Bolivia, la opción de control fue la profesionalización para alejarlos de la política ${ }^{29}$, a pesar de lo cual, desde 1924 las intervenciones militares fueron decisivas para modificar el Estado y la economía.

En todo caso, después de 1883 la supremacía civil encontró problemas, porque, por una parte, los militares debían ser una fuerza estable para enfrentar un escenario de amenazas reales de guerra internacional, generado por las nuevas fronteras con Perú, Bolivia y Argentina, y, por otra, debían reprimir los descontentos populares y asumir tareas de seguridad pública, todo lo cual alcanzó su clímax con la matanza de la escuela de Santa María de Iquique, en 1907, mediante una operación conjunta de fuerzas navales y terrestres. Posteriormente se trataron de alejar de la represión masiva; así, desde 1908 el Ejército apoyó el uso de las tropas de Carabineros como policía, bajo el mando del Ministerio del Interior ${ }^{30}$. A la larga la conflictividad social fue contenida y no derivó en revueltas agrarias ni en revoluciones burguesas ${ }^{31}$. En ese sentido las intervenciones militares fueron decisivas para remodelar el Estado y marcar a la sociedad ${ }^{32}$.

\section{IDEAS ECONÓMICAS, TECNOLOGÍA Y ESTADO}

Los procesos anteriores tuvieron correspondencia con las tendencias económicas e internacionales que forjaron a los militares. Para autores como Quiroga, la adopción del modelo alemán por parte del Ejército desde 1887, les habría entregado nociones nacionalistas, idolatría estatal y rechazo al liberalismo como sistema político $^{33}$. Para Salazar, Mancilla y Durán ese influjo, poco antes de la Primera Guerra Mundial, habría sintonizado con el interés del capitalismo alemán, basado en trust industriales, por instalar en Chile, hacia 1912, una fábrica de máquinas y herramientas, en los momentos en que había una discusión pública sobre naciona-

28 Jocelyn-Holt, op. cit., 27; Ana María Stuven, "Una aproximación a la cultura política de la elite chilena: concepto y valoración del orden social (1830-1860)", en Estudios Públicos, $\mathrm{N}^{\circ}$ 66, Santiago, 1997, 259-311.

29 Valenzuela y Valenzuela, op. cit., 34-35; Quiroga, "Fuerzas armadas", op. cit., 113.

30 Peter DeShazo, Urban Workers and Labour Unions in Chile, 1902-1927, Madison, The University of Wisconsin Press, 1983; Eduardo Devés, Los que van a morir te saludan. Historia de una masacre: Escuela Santa María de Iquique, 1907, Santiago, Lom Ediciones, 1997; Carlos Maldonado, "Los Carabineros de Chile: Historia de una policía militarizada", en Ibero-Americana. Nordic Journal of Latin American Studies, Vol. XX, Estocolmo, 1990, 3-31.

31 Sobre revoluciones burguesas frustradas y ausencia de rebeliones campesinas, véase José Bengoa, El poder y la subordinación. Acerca del origen rural del poder y la subordinación en Chile, Santiago, Sur Ediciones, 1988; Mario Garcés, Crisis social y motines populares en el 1900, Santiago, Ediciones Documentas-ECO Educación y Comunicaciones, 1991; Tomás Moulian, Chile actual: anatomía de un mito, Santiago, Lom Ediciones-Universidad ARCIS, 1997.

32 Joxe, op. cit., 43.

33 Quiroga, "Fuerzas armadas", op. cit., 113. 
lismo e industrialismo, en la que participaban industriales, ingenieros, movimiento obrero y militares. Sin embargo, la guerra en Europa y el alineamiento comercial con Gran Bretaña habrían frustrado ese cambio, aunque para la década de 1920 ese influjo habría persistido y se habría manifestado en un pensamiento económico distinto al capitalismo británico, cuyas firmas comerciales y financieras promovían la exportación de materias primas, haciendo dependiente a la estructura económica chilena de la importación de tecnología ${ }^{34}$. Para Valdivia, en tanto, todo ello habría estructurado en la década de 1920 una "tendencia desarrollista-estatista" de los militares, la cual se habría prolongando un poco más allá de $1973^{35}$.

Varios aspectos de las tesis anteriores son discutibles y los confrontaremos con la evidencia que presentamos más adelante. A nuestro juicio, esos influjos no crearon una doctrina articulada para establecer una visión institucional supraclasista e intervencionista del Estado, que desplazara a la iniciativa privada y al mercado. Para esto es necesario señalar -brevemente por razones de espacio-, el marco de ideas, políticas e instituciones. Las influencias destacadas por estas tesis fueron relativas, primero porque la atención se concentra en el Ejército, ignorando a la Armada, que era más tecnificada y capaz de inclinar la balanza de poder, algo que había demostrado desde 1891, cuando incrementó su peso en la política interna, a través de la llegada a la presidencia de la República del vicealmirante Jorge Montt, entre 1891 y $1896^{36}$. En segundo lugar debe considerarse que, si bien Chile tenía una economía liberal, también tenía un Estado con rasgos intervencionistas, bajo control civil, que contó con una pequeña pero significativa tecnocracia de ingenieros en varias agencias públicas.

A diferencia de países en que los militares podían reivindicarse como un sector técnico más avanzado, en Chile las condiciones eran otras. Cuando las Fuerzas Armadas empezaron a crecer, ya existían agencias y ministerios técnicos, como la Empresa de Ferrocarriles del Estado (EFE), de 1884, el Ministerio de Industrias y Obras Públicas, de 1887, y la Dirección de Obras Públicas (DOP), de 1888, a la vez que un Instituto de Ingenieros que influía en las políticas públicas y en órganos de representación como la Sociedad de Fomento Fabril (SOFOFA). También fueron muy decisivos los referentes internacionales que nutrieron el Estado chileno.

Además de los militares, en el ámbito civil las opciones en el plano tecnológico y comercial fueron decisivas. La EFE y entidades como la DOP fueron controladas por ingenieros formados en la Universidad de Chile y en Bélgica, país que entre la década de 1870 y 1914 fue el referente de los ingenieros chilenos -sustituido

34 Salazar "Los límites", op. cit., 104-105; Gabriel Salazar, Arturo Mancilla y Carlos Durán, "Estado, legitimidad, ciudadanía", en Gabriel Salazar y Julio Pinto (eds.), Historia contemporánea de Chile I, Santiago, Lom Ediciones, 1999, 158.

35 Verónica Valdivia Ortiz de Zárate, El golpe después del golpe. Leigh vs. Pinochet. Chile 1960-1980, Santiago, Lom Ediciones, 2003.

36 Monteón, Chile in the Nitrate, op. cit., 57-119; Nunn, op. cit., 34; Philip Somervell, "Naval Affairs in Chilean Politics, 1910-1932", en Journal of Latin American Studies, Vol. 16, No 2, Cambridge, 1984, 382. Respecto a la importancia de la Marina de guerra dentro de una visión temporal amplia para el siglo XIX, véase Patricia Arancibia, Isabel Jara y Andrea Novoa, La marina en la historia de Chile, tomo I: Siglo XIX, Santiago, Sudamericana, 2005. 
después por Estados Unidos y, en menor medida, por Alemania-, que fue escogido por su temprano desarrollo de empresas y obras públicas y que entregó a los ingenieros misiones y herramientas nítidas sobre el papel que debían desarrollar en el Estado. De esa manera, Alemania no fue el único referente para el aparato estatal chileno: así, por ejemplo, EFE adoptó como proveedor y modelo a los Estados Unidos y a Bélgica y la Marina de guerra se mantuvo ligada a Inglaterra e incluso en la década de 1890 compró armamento francés ${ }^{37}$.

En el Estado chileno, quienes tenían el comando de las opciones productivistas y técnicas eran los ingenieros, lo que se mantuvo así a lo largo del siglo XX, hasta el punto de que los economistas, grupo que los sucedió, crearon figuras híbridas como los ingenieros comerciales e industriales, para no entrar en competencia. En el Estado y del mercado chileno convivían varias opciones internacionales que no lograron ser implantadas hegemónicamente por ningún grupo, ni menos ser impuestas por los militares a otros actores.

Otro aspecto que debe considerarse fue la tendencia chilena a aplicar modelos en versiones cercanas a la ortodoxia. Esa conducta se conformó desde la década de 1830, acorde a una economía abierta y especializada en materias primas, y se perfeccionó en las aulas y en el gobierno, cuando, en 1855, se contrató al economista liberal francés Jean Gustave Courcelle-Seneuil, como asesor del Ministerio de Hacienda y profesor de la Universidad de Chile, enfrentándose las posturas de laissez-faire con las neomercantilistas que enfatizaban en el proteccionismo e intervención del Estado en la economía. Ello ocurrió en 1858 con la creación de la primera empresa estatal de servicios, el Ferrocarril entre Santiago y Valparaíso, y más tarde con el ciclo salitrero, el cual tuvo un impacto en dos sentidos: integró estrechamente al país a la economía internacional y amplió las tareas del Estado ${ }^{38}$. Se crearon las condiciones para dar un giro hacia planteamientos como los de Friedrich List, quien, en su Sistema nacional de economía política (1841), señaló que el proteccionismo y el control de las fuerzas económicas del exterior harían posible la industrialización y el crecimiento así como la unidad nacional y el mercado interno. Representante de esas ideas fue Daniel Martner, economista, ministro y rector de la Universidad de Chile, quien en Nuestros problemas económicos planteó que el país debía seguir las ideas propugnadas por List, respecto de movilizar las fuerzas productivas para salir de su condición ${ }^{39}$.

37 Guillermo Guajardo, "Les modeles industriels induits par le développement du chemin de fer en Amérique latine (1850-1950)", en Économies et Sociétés, Série F, tomo 35, N 9-10, París, 2001, 1.415-1.437.

38 Robert M. Will, "The Introduction of Classical Economics into Chile”, en Hispanic American Historical Review, Vol. 44, $\mathrm{N}^{\circ}$ 1, Duke, 1964, 1 y 20-21; Sergio Villalobos, Los comienzos de la historiografía económica de Chile, 1862-1940, Santiago, Editorial Universitaria, 1981, 28-29; Andrés Sanfuentes, "La deuda pública externa de Chile entre 1818 y 1935", Santiago, CIEPLAN, Serie Notas Técnicas, N 96, Santiago, 1987, 1-32; Harold Blakemore, "Chile, desde la guerra del Pacífico hasta la depresión mundial, 1880-1930”, en Leslie Bethell (edit.), Historia de América Latina, Vol. 10, América del Sur, c. 1870-1930, Barcelona, Cambridge University Press-Crítica, 1992, 157-203.

39 Friedrich List, Sistema nacional de economía política, México, Fondo de Cultura Económica, 1997, 240-241; Daniel Martner, Nuestros problemas económicos, Santiago, Sociedad Imprenta y Litografía Barcelona, 1918. 
Catalizadora de esas tendencias fue la Primera Guerra Mundial, que brindó ejemplos de impulso de industrias militares y de la necesidad de controlar recursos para un esfuerzo de guerra. Pero, tal como mostraremos más adelante, el interés por tener una capacidad productiva local para la guerra fue planteado más bien desde el gobierno civil que desde las Fuerzas Armadas. Este fue el antecedente para potenciar, desde la década de 1920, las ideas nacionalistas y antiliberales -algunas influidas por la visión de Spengler-, que identificaron democratización con "crisis moral" de la sociedad, cuando avanzaban nuevos actores sociales y políticos ${ }^{40}$, y que crearon un ambiente favorable para que amplios sectores vieran con simpatía el autoritarismo del general Carlos Ibáñez del Campo (1927-1931) y simpatizaran con el inicial fascismo y nacionalsocialismo. La paradoja fue que Ibáñez del Campo no militarizó el Estado y tomó una orientación opuesta a los intereses pro germánicos, ya que incentivó la inversión estadounidense en la minería, los servicios y la industria ${ }^{41}$.

La vuelta al gobierno civil, con Arturo Alessandri en octubre de 1932, tuvo un impacto severo sobre las Fuerzas Armadas, especialmente en el Ejército, que se vio afectado por la expulsión de oficiales, reducción de tropa y presupuesto y el contrapeso que le hicieron, hasta 1936, cuerpos paramilitares como la Milicia Republicana, que tenía similitud con los freikorps alemanes de la posguerra, las milicias nazis y las guardias cívicas de otros países latinoamericanos ${ }^{42}$. Pero con esto no se crearon condiciones para corrientes fascistas y populistas en las Fuerzas Armadas; el nacionalsocialismo criollo se redujo a un partido político pequeño, al punto de que, según apuntó Stanley G. Payne, dentro del contexto internacional el de Chile fue casi el único caso que, para fines de la década de 1930, promovía y se desenvolvía en una democracia liberal ${ }^{43}$. Si bien es cierto que permanecieron algunos oficiales ultranacionalistas en el Ejército que pretendían un tercer camino entre el capitalismo y el socialismo, estos sufrieron un duro revés cuando Chile rompió relaciones en 1943 con el eje fascista, desarticulándose los grupos simpatizantes dentro de las Fuerzas Armadas ${ }^{44}$.

40 Gabriel Salazar, "Historiadores, historia, estado y sociedad. comentarios críticos en torno al Ensayo histórico sobre la noción de estado en Chile en los siglos XIX y XX, de Mario Góngora”, en Nueva Historia. Revista de historia de Chile, año 2, № 7, Londres, 1983, 193-201; Cristián Gazmuri, Testimonios de una crisis. Chile: 1900-1925, Santiago, Editorial Universitaria, 1980.

41 Francisco Domínguez, Carlos Ibánez del Campo: Failed Dictator and Unwitting Architect of Political Democracy in Chile, 1927-31, en Will Fowler (ed.), Authoritarianism in Latin America since Independence. Westport, Conn. and London, Greenwood Press, 1996, 47-57; Michael Monteón, Chile and the Great Depression. The Politics of Underdevelopment, 1927-1948, Tempe, Ariz., Arizona State University, 1998.

42 Carlos Maldonado, La Milicia Republicana. Historia de un ejército civil en Chile, 1932/1936, Santiago, Servicio Universitario Mundial, 1988; Marcus Klein, "White Guards, Reactionaries or Fascists?: A Comparison of the Legión Cívica Argentina and the Milicia Republicana", en Bicentenario, Vol. 4, N ${ }^{\circ}$ 1, Santiago, 2005, 65-80.

43 Stanley G. Payne, A History of Fascism, 1914-1945, Madison, The University of Wisconsin Press, 1995, 342 .

44 Si bien en la década de 1930 hubo una extendida influencia, tanto del estado nacionalsocialista como de los movimientos nazis en sectores de la oficialidad de las fuerzas armadas chilenas, la ruptura con el Eje, en 1943, puso en evidencia el peso de la relación económica y estratégica que Chile venía cultivando con Estados Unidos y que se proyectaría por el resto del siglo. Frente a las simpatías 
A su vez, los militares quedaron desfasados ideológicamente de sus posibles aliados civiles. Después de 1934 surgió una síntesis conservadora, que fusionó una visión elitista y antidemocrática en lo político y antiestatista en lo económico, y tras la derrota del Eje, en 1945, la derecha tomaría distancia del Estado, porque tanto el socialismo como el fascismo habían aplicado soluciones estatales a los problemas de producción, con una amplia movilización de masas ${ }^{45}$. Todo lo cual marcaría un nuevo giro, del que surgió una generación de economistas opuestos a toda forma de intervención, inspirados en Friedrich Hayek, quien en 1944 identificó la tiranía con las políticas socialistas y la planificación económica ${ }^{46}$.

Después de esos giros en ideas y modelos, las Fuerzas Armadas quedaron excluidas del modelo de desarrollo, sobre todo tras la creación de la CORFO, cuyos primeros planes fueron elaborados por organizaciones empresariales e ingenieros.

\section{UN ESQUEMA SOBRE APRENDIZAJES TECNOLÓGICOS Y PROYECTOS ECONÓMICOS}

Tomando en cuenta lo anterior, se puede afirmar que hasta 1913, en un período de fuerte inserción a la economía internacional, el país expandió sus territorios a la vez que aumentó la importancia y armamento de las Fuerzas Armadas. Pero partir de la Primera Guerra Mundial, empezaron a manifestarse tendencias antiglobalizantes que se tradujeron en una caída en el crecimiento chileno, que pasó de un PIB máximo de $12,2 \%$ en 1910 a tasas inestables e incluso negativas después de 1918 , hasta llegar en 1933 a un menos $23 \%$ general y menos $24 \%$ per cápita ${ }^{47}$. Es decir, los planes y acciones de los militares en la política y, en menor medida en la economía, se dieron en un contexto de deterioro de la relación de Chile con la economía internacional. Esto permite señalar que los proyectos del Ejército, desde este momento, tendieron a plantearse el desarrollo de una capacidad local, al no contar desde 1918 con un socio internacional seguro, por la derrota de Alemania; mientras que en la Armada más bien se dirigieron a mejorar su capacidad de mantenimiento y asegurar el vínculo con Gran Bretaña.

germanas, el influjo estadounidense -en ese entonces- no mostraba el efecto de politización que sí tenía sobre los militares la relación con Alemania. Por esto no es extraño que la parte "pro aliada" del gobierno colaborara activamente en elaborar listas negras y penalizaciones sobre las redes nazis. Sobre estos aspectos, véase Raffaele Nocera, Chile y la guerra 1933-1943, Santiago, Lom Ediciones, 2006; Id., "Ruptura con el eje y alineamiento con Estados Unidos: Chile durante la Segunda Guerra Mundial", en Historia, No 38, Vol. II, Santiago, 2005, 397-444; Macarena Carrió y Joaquín Fermandois, "Europa occidental y el desarrollo chileno 1945-1973", en Historia, No 36, Santiago, 2003, 7-60; Max Paul Friedman, Nazis and good neighbors: the United States campaign against the Germans of Latin America in World War II, Cambridge-New York, Cambridge University Press, 2003; María Soledad de la Cerda, Chile y los hombres del Tercer Reich, Santiago, Editorial Sudamericana, 2001; Víctor Farías, Los nazis en Chile, Barcelona, Seix Barral, 2000.

45 Renato Cristi y Carlos Ruiz, "Pensamiento conservador en Chile (1903-1974)", en Eduardo Devés, Javier Pinedo y Rafael Sagredo (coords.), El pensamiento chileno en el siglo XX, México, Fondo de Cultura Económica - Ministerio Secretaría General de Gobierno de Chile - Instituto Panamericano de Geografía e Historia, 1999, 84-92.

46 Friedrich Hayek, Camino de Servidumbre, Madrid, Alianza Editorial, 2000, 33.

47 Díaz, Lüders y Wagner, op. cit., 59 y 97-99. 
Los proyectos de las Fuerzas Armadas, tanto los anteriores como los posteriores al cambio de escenario producido por la Primera Guerra Mundial, persiguieron dos gruesos objetivos: el primero, desarrollar industrias metalmecánicas y de ingeniería estatales, y en menor medida privadas, para surtir sus necesidades en tiempos de paz y, de ser posible, en la guerra; y el segundo, tomar el control de sectores claves de la infraestructura para asegurar la movilidad de las fuerzas militares, propósito que el Ejército intentó conseguir a través de los ferrocarriles y la Armada por medio de soluciones de mercado, desarrollando sus propios astilleros y vendiendo servicios.

Esos objetivos se desenvolvieron en cuatro períodos:

Entre 1865 y 1887, se implantaron capacidades de ingeniería mecánica destinadas a cubrir las necesidades de bienes y servicios metalmecánicos del Ejército y la Armada. Los planteamientos están poco perfilados como proyectos de defensa y provienen de iniciativas civiles y estatales, en especial durante la guerra contra España (1865) y la Guerra del Pacífico (1879-1883). Las maestranzas de los ferrocarriles estatales y contratos con firmas privadas asumieron esas tareas durante la guerra.

Entre 1890 y 1913, se dio una carrera armamentista acompañada de profesionalización técnica, con demandas por soporte estatal para ampliar y desarrollar armamento en talleres, arsenales y astilleros.

Entre 1914 y 1923 surge la idea de coordinación económica para la defensa nacional, como producto de las experiencias de la Primera Guerra Mundial en Europa, que se manifiesta desde 1917 con la aparición de un pensamiento militar más articulado en torno a la economía y defensa nacional, así como de algunas expresiones -no realizaciones- de nacionalismo económico. La guerra europea planteó el ejemplo de la coordinación de la industria y medios de transporte en manos del Estado.

Entre 1924 y 1932, muchos de los proyectos militares se traducen en la ampliación de las capacidades de los talleres, arsenales y astilleros del Ejército y la Armada, el alto mando cierra filas con el gobierno civil frente a las propuestas militares que querían invadir el ámbito empresarial.

Por otra parte, en esos períodos hemos detectado cuatro actores que jugaron varias interacciones:

Un conglomerado empresarial monopólico importador-exportador, que controla el comercio exterior chileno, del cual dependen los ingresos del Estado. Este se localiza en el sector primario y en los servicios financieros y mercantiles, mediante asociaciones entre el capital extranjero y nacional.

Un grupo de industrias que surten el mercado interno, conformado por empresas chilenas cuyo núcleo lo constituyeron fundiciones de Valparaíso y Santiago desde la década de 1870, sus mayores intereses están aglutinados desde 1883 en la SOFOFA.

Los manufactureros artesanales, grupo de baja composición de capital, orientado al mercado interno popular de bienes de consumo básico, pero no de bienes de capital industriales y militares. Estos podían cubrir necesidades de consumo inme- 
diato de las Fuerzas Armadas, como ropa, correajes y material de aseo controlados por el conglomerado importador-exportador. Ejemplo de esto es que en la década de 1890 el gobierno suscribió un contrato con una sola firma que importaba cerca de 1.000 artículos de consumo para los buques de la Armada que incluía escobas y jabón ${ }^{48}$, que podían ser provistos por productores populares.

Y, por último, una serie de establecimientos estatales industriales de alta composición de capital y tecnología , que cubrían las necesidades de mantenimiento de las Fuerzas Armadas, los ferrocarriles estatales y las obras públicas, a la vez que comprendían los talleres de escuelas técnicas, como la Escuela de Artes y Oficios en Santiago, desde 1890. Un actor menor fueron los talleres de las cárceles.

Dentro de este último grupo es necesario separar un subsector, conformado en el Ejército por los talleres de la fábrica de cartuchos que dieron origen a Fábricas y Maestranzas del Ejército (FAMAE), encargado de proveer municiones y una diversidad de bienes metálicos, y en la Armada por los astilleros y talleres mecánicos de reparación de naves, artillería y maquinaria, articulados en torno a los Astilleros y Maestranzas de la Armada (ASMAR).

Nuestro análisis se concentrará en las acciones del grupo conformado por los establecimientos y reparticiones técnicas del Ejército y la Armada, que en general no recibieron apoyo del Estado. En ese esquema para los empresarios industriales del mercado interno la guerra no fue negocio, pues no hubo una burguesía industrial "guerrera", el verdadero empresariado bélico fue el conglomerado importador y exportador que impulsó nuevas fuentes de negocios para sí y una fuente fiscal para el Estado. Las interacciones indican que hubo una constante derrota de los manufactureros artesanales y la contención de los establecimientos estatales que en el largo plazo benefició a los importadores e industriales. Se puede afirmar que el pensamiento del alto mando nunca fue productivista; incluso durante la década de 1920, los establecimientos militares debieron disputarle a los industriales metalúrgicos los contratos del Estado. La expansión y modernización de los militares dependía de la relación del Estado con los importadores, ya que su capacidad de fuego no se basaba en el desarrollo de la industria local ni de un mayor desarrollo de los establecimientos estatales, lo que hizo que las corrientes nacionalistas no encontraran apoyo en los empresarios industriales, lo cual nos entrega un mapa para entender la trayectoria que analizaremos en las siguientes secciones.

\section{UNA COLISIÓN INICIAL: INGENIERÍA MILITAR VERSUS INGENIERÍA CIVIL}

¿Por qué los militares no lograron el apoyo de otros actores sociales y económi$\cos$ ?

A diferencia de los militares de Argentina, Brasil, Ecuador y Perú, que desde la década de 1920 se involucraron en proyectos de industrias de defensa y en el

48 "Aprovisionamiento de los buques", en Revista de Marina (en adelante RdeM), tomo XXII, N ${ }^{\circ}$ 128, Valparaíso, 1897, 123-129. 
control estatal de los recursos naturales, los militares chilenos no desarrollaron la ingeniería ni la infraestructura necesaria para llevar adelante un proyecto de alcance mayor ${ }^{49}$. A pesar de esto, sí es posible encontrar ideas y acciones que los enfrentaron a los civiles; una actividad importante en que se manifestó esa colisión inicial fue la ingeniería.

Durante el dominio colonial español, la ingeniería fue una profesión militar desarrollada en la construcción de fortificaciones y obras públicas ${ }^{50}$, pero después de la Independencia la ingeniería se hizo más "civil", a diferencia de lo que ocurría en países como Argentina, Brasil o Colombia, donde las escuelas militares también formaban ingenieros, como reflejo de las tendencias del mundo occidental de combinar la instrucción militar con la ingeniería civil ${ }^{51}$. En Chile, en cambio, los militares no contaron con una formación especial ni autónoma en ingeniería hasta bien entrado el siglo XX, como tampoco en sus escuelas se cultivó el positivismo. Por esto, a pesar de que en 1845 el Ejército estableció el Cuerpo de Ingenieros y en 1863 se creó la Oficina de Ingenieros Militares, la vinculación con los trabajos públicos fue cancelada tempranamente con la creación, en 1842, del Cuerpo de Ingenieros Civiles, para construir y dar mantenimiento a los caminos públicos, entidad que quedó bajo el control del Ministerio del Interior. Fue recién en 1953 cuando se organizó, en el Ministerio de Defensa, un servicio militar para apoyar los trabajos públicos.

El resultado fue que el personal técnico y de ingenieros militares no se formó ni concibió como una élite técnica en contacto con la universidad, sino que sus bases de calificación fueron los talleres de reparación de la artillería y la fabricación de

49 Rosemary Thorp, Progress, Poverty, and Exclusion: An Economic History of Latin America in the 20th Century, Washington D.C., Inter American Development Bank, 1998, 120-121, 163 y 183; Stefan de Vylder, "Chile 1973-1987: los vaivenes de un modelo", en Rigoberto García (coord.), Economía y política durante el gobierno militar en Chile, 1973-1987, México, Fondo de Cultura Económica, 1989, 57; Jorge Schvarzer, La industria que supimos conseguir. Una historia políticosocial de la industria argentina, Buenos Aires, Planeta, 1996, 179. Sobre los casos de Brasil y Perú, véase Ben Ross Schneider, Politics within the State: Elite Bureaucrats and Industrial Policy in Authoritarian Brazil, Pittsburgh, Pa., University of Pittsburgh Press, 1991; Mauricio Mesquita, Industrialization, Trade, and Market Failures: The Role of Government Intervention in Brazil and South Korea, New York, St. Martin's Press, 1995; Alfred Stepan, The State and Society: Peru in Comparative Perspective, Princeton, Princeton University Press, 1978.

50 Jaime Rosenblitt, "La ingeniería militar en el Chile hispano", en Mapocho, $\mathrm{N}^{\circ}$ 54, Santiago, 2003, 221-228; Alicia Cámara (ed.), Los ingenieros militares de la monarquía hispánica en los siglos XVII y XVIII, Madrid, Coedición Asociación Española de Amigos de los Castillos - Centro de Estudios Europa Hispánica, Ministerio de Defensa, 2005; Horacio Capel et al., Los ingenieros militares en España, siglo XVIII: repertorio biográfico e inventario de su labor científica y espacial, Barcelona, Edicions Universidat de Barcelona: Cátedra de Geografía Humana, 1993; Horacio Capel, Joan Sánchez y Omar Moncada, De Palas a Minerva: La formación científica y la estructura institucional de los ingenieros militares en el siglo XVIII, Barcelona, Serbal; Madrid, C.S.I.C., 1988.

51 Paul Forman y José M. Sánchez-Ron (eds.), National Military Establishments and the Advancement of Science and Technology: Studies in 20th Century History, Dordrecht, Kluwer Academic Publishers, 1996; Simon Schwartzman, A Space for Science: the Development of the Scientific Community in Brazil, University Park, Pennsylvania State University, 1991; Frank Safford, The Ideal of the Practical: Colombia's Struggle to Form a Technical Elite, Austin, University of Texas Press, 1976; María Haydée Martín, Alberto S. J. de Paula y Ramón Gutiérrez, Los ingenieros militares y sus precursores en el desarrollo argentino hasta 1930, Buenos Aires, Fabricaciones Militares, 1976. 
municiones, la instalación de líneas telegráficas, la operación de trenes militares, el mantenimiento de las naves de guerra, la reparación de maquinarias de vapor, motores y dínamos, así como la fundición y forja de artículos metálicos.

Algunos recintos e instituciones destacaron en la formación de personal técnico. En el Ejército tal tarea la asumió la Fábrica de Armas, creada en 1811, que más tarde sería la Fábrica de Cartuchos y en el siglo XX el complejo Fábricas y Maestranzas del Ejército (FAMAE); otros fueron los talleres de la Dirección de Material de Guerra y el Batallón de Ferrocarrileros, que se constituyó en una de las primeras e importantes unidades de ingeniería. Esas capacidades maduraron en 1926 con la creación de la Academia Técnica Militar, destinada a formar a los ingenieros del Ejército, que inició sus actividades dentro de FAMAE y que en 1947 se convirtió en la Academia Politécnica Militar ${ }^{52}$.

En la Armada los espacios de formación fueron los barcos de vapor, en particular las fragatas blindadas y los acorazados adquiridos en las décadas de 1870 y 1880 , que aceleraron el cambio tecnológico e institucional. En 1896 se dieron los pasos necesarios para superar el estado de atraso técnico, con la construcción del Dique Seco de Carenas $\mathrm{N}^{\circ}$ 1, en la bahía de Concepción, y de los Arsenales de Marina y la Escuela de Aspirantes a Ingenieros Mecánicos (EIM), en Valparaíso, que inició sus actividades en los Arsenales de Marina ${ }^{53}$. La compra de un acorazado Dreadnought, el "Almirante Latorre", condujo a la construcción del Dique Seco N² 2, en 1924, en el puerto militar de Talcahuano, punto en que se desarrollaría el mayor complejo naval de Chile, los Astilleros y Maestranzas de la Armada (ASMAR) ${ }^{54}$.

Desde esos espacios, las ideas y proyectos militares irían escalando en complejidad y peligrosidad política, hasta llegar a cuestionar las bases de una economía especializada en la exportación de materias primas.

Algo distinto ocurrió en el ámbito civil. Desde mediados del siglo XIX los hijos de la élite chilena empezaron a estudiar ingeniería en la Universidad de Chile, interés que ya en 1871 era percibido como un intento "tal vez de que no se les escape la dirección de la política" 55 . La titulación de ingenieros en la Universidad de Chile, a partir de la década de, 1860 se acompañó del envío de estudiantes a Bélgica, donde tomaron contacto con los primeros "empresarios públicos", que participaban en la construcción y operación de caminos, puertos y ferrocarriles ${ }^{56}$.

52 Chile. Ejército de Chile, División Escuelas, Academia Politécnica Militar, Proyecto educativo Academia Politécnica Militar año 2006, Santiago, Ejército de Chile, 2006, 3; Orlando Jacobelli, Curso de tecnología y construcción mecánicas dictado en la Academia Técnica Militar, Santiago, Escuela de Ingenieros Militares, 1938; F. J. Díaz, Apuntes de fortificaciones de campaña redactados sobre la base de la $3 a$. parte del reglamento alemán para dicho ramo, Santiago, Escuela de Ingenieros Militares, 1924.

53 Chile. Ministerio de Marina, Memoria anual del Ministerio de Marina (en adelante MMM), Santiago, Imprenta Nacional, 1897, 17; MMM, 1900, X.

54 Chile. Astilleros y Maestranzas de la Armada, ASMAR es la empresa que posee los principales astilleros chilenos, Concepción, Impresos Andalién, 1978.

55 Félix Echeverría, "Las máquinas y el trabajador agrícola", en Boletín de la Sociedad Nacional de Agricultura, Vol. II, $\mathrm{N}^{\circ} 21$, Santiago, 1871, 378.

56 Guajardo, Tecnología..., op. cit., 25-26. 
Las capacidades de ingeniería se desplegaron en gran forma desde la década de 1880. La derrota militar de Perú y Bolivia trajo la anexión a Chile de ricos territorios mineros, incrementó los ingresos públicos y permitió lanzar un amplio programa de obras. Los ingenieros se ubicaron en el centro de las decisiones estatales, a través de una nueva generación de instituciones que les entregaron bases para su autonomía y cohesión gremial. Instituciones destacadas fueron EFE, MIOP, DOP y, como organismo gremial desde 1888, el Instituto de Ingenieros. La creación, en 1927, del Ministerio de Fomento les dio capacidad para intervenir en diversos ámbitos de la economía ${ }^{57}$ e, incluso después de la Depresión de 1929, la intervención pública y la rudimentaria planeación económica seguirían en manos de los ingenieros civiles, sin que otros grupos les disputaran su posición dentro del Estado ${ }^{58}$.

En el largo plazo, los militares se vieron limitados tanto por el dominio político de la élite como por la tecnocracia. Llegaron con sus armas, pero tarde y con debilidades en su profesionalización técnica. Además, no hubo cooperación entre ambos grupos, es decir entre los establecimientos militares y la industria que abastecía el mercado interno, sino una competencia por recursos y favores del Estado.

\section{CAPACIDADES TECNOLÓGICAS Y MILITARES: UN ACCIDENTADO CAMINO}

Después de las guerras de Independencia, tanto el Ejército como la Marina de guerra chilenos decrecieron en importancia; para 1847 el primero tenía 1.661 hombres y la Armada 3 buques y 147 hombres. Esa situación cambió a partir de 1854, cuando se contrató en Inglaterra la construcción de la corbeta Esmeralda, de 850 toneladas y 200 caballos de fuerza $(\mathrm{HP})^{59}$, que prestaría útiles servicios en los conflictos internacionales de la década siguiente como en 1863, cuando hubo una amenaza de guerra con Bolivia, por problemas de límites, y dos años más tarde cuando España atacó las costas chilenas ${ }^{60}$. Este último escenario impulsó la creación de la Fundición Nacional, en 1865, para fundir cañones, que fue instalada en la estación de Limache del ferrocarril entre Santiago y Valparaíso. Al terminar el conflicto con España, la Fundición Nacional continuó su actividad, manufacturando maquinarias y herramientas para la agricultura y la industria, razón por la cual,

57 Santiago Marín Vicuña, Nuestros ingenieros, Santiago, Editorial Nascimento, 1935; Santiago Marín Vicuña, Los ferrocarriles de Chile, Santiago, Imprenta Cervantes, 1916; Win Crowther, "Technological Change as Political Choice: The Civil Engineers and the Modernization of the Chilean State Railways", Ph.D. Thesis. Department of Political Science, University of California, Berkeley, 1973; Adolfo Ibáñez Santa María, "El liderazgo en los gremios empresariales y su contribución al desarrollo del Estado moderno durante la década de 1930. El fomento de la producción y los antecedentes de la CORFO", en Historia, No 28, Santiago, 1994, 183-216.

58 Jorge Soto Vásquez, "Ideas para tecnificar el Estado chileno. El caso del personal político y administrativo, 1900-1920", en Intus Legere, No 7, Vol. 2, Santiago, 2004, 91-109.

59 Eugenio Chouteau, "Relación de los diversos estados por los que ha pasado en Chile la escuadra, la escuela náutica y la escuela naval", en $R d e M$, tomo I, N ${ }^{\circ} 3,1885,242-244$; tomo I, N ${ }^{\circ} 6$, 1885,649 ; tomo II, $\mathrm{N}^{\circ} 1,1886,8$.

$60 \quad M M M, 1865,8-9$; "Memoria de la Comandancia general de marina, 1872. Buques de la escuadra”, en Archivo Nacional, Fondo Ministerio de Marina, Vol. 30. 
en 1870 , su director pidió al gobierno autorización para ampliar los talleres y atender pedidos civiles. Sin embargo, apareció una fuerte oposición a su expansión, tanto por parte del gobierno como de los empresarios, lo que quedó de manifiesto en 1872, durante la exposición industrial de ese año, cuando los talleres del Ferrocarril entre Santiago y Valparaíso, los talleres del Ejército, la Fundición Nacional y la Escuela de Artes y Oficios (EAO) presentaron máquinas, locomotoras, carros y herramientas, que constituían la muestra más importante, a pesar de todo no recibieron el primer premio, debido a que eran "talleres del Estado" 61.

El sector empresarial, temeroso de las capacidades manufactureras del Estado, logró que finalmente en 1874 la Fundición Nacional fuera cerrada por Aníbal Pinto, ministro de Guerra y futuro Presidente de la República, entre 1876 y 1881, por dar una "competencia inmotivada" a los establecimientos privados. En 1875 se determinó que se conservaran solo las máquinas para armas, "sin aplicación a los talleres de la industria privada". Para 1879, cuando estalla la Guerra del Pacífico, no se contaba ya con ese establecimiento ni había previsiones para el conflicto, por los recortes de presupuesto debidos a la depresión económica de mediados del decenio. Para superar las dificultades, el gobierno de Pinto involucró a civiles en la logística y en el mando de la guerra, cuestionando así la capacidad de los oficiales ${ }^{62}$. No fue reabierta la Fundición Nacional, pero los talleres de los ferrocarriles estatales debieron fabricar municiones, reparar fusiles, fortificaciones y calderas ${ }^{63}$, y se hicieron contratos con firmas metalúrgicas privadas que atendieron las necesidades de las Fuerzas Armadas ${ }^{64}$.

Después de 1883, los nuevos territorios adquirieron gran importancia militar, razón por la cual los oficiales de la escuadra debían visitar las instalaciones salitreras en Antofagasta y hacer estudios estratégicos en el interior de esa provincia ${ }^{65}$. A ese escenario se sumó otro en el extremo sur, por la controversia de límites con Argentina, que hizo necesaria una escuadra de alta mar, tal como lo expuso en 1885 el ministro de Marina Carlos Antúnez, en el sentido de que Chile necesitaba "una escuadra poderosa que sirva no tan solo para garantir su autonomía sino también para dar vida y estabilidad a su comercio" 66 .

61 Exposición Nacional de Artes e Industria de 1872, Memorias premiadas en el certamen y documentos que les siguen de antecedentes, Santiago, Imprenta de la República, 1873, XVI, LXXXIILXXXIII y LVI; Luis Ortega, “Acerca de los orígenes de la industrialización chilena, 1860-1879”, en Nueva Historia. Revista de historia de Chile, $\mathrm{N}^{\circ}$ 1, Londres, 1981, 3-54.

62 Ibid., 42; Chile. Ministerio de Guerra y Marina, Memoria correspondiente al año 1875, XXXII; William Sater, Chile and the War of the Pacific, Lincoln, University of Nebraska Press, 1986, $17-18$ y $34-35$.

63 "Informe de la Superintendencia del Ferrocarril entre Santiago y Valparaíso. Departamento de Locomotoras y Maestranza, 31 de diciembre de 1880". Archivo Nacional, Fondo Ministerio del Interior, Vol. 864; "Informe del Ferrocarril entre Santiago y Valparaíso correspondiente a 1880", en Chile. Ministerio del Interior, Memoria correspondiente al año 1880, 49-50; "José M. Ureta, Superintendente del Ferrocarril del Sur al Ministro del Interior, 31 de diciembre de 1880", en Archivo Nacional, fondo Ministerio del Interior, Vol. 865.

${ }^{64}$ Guillermo Guajardo, "Una perspectiva histórica sobre los eslabonamientos industriales 'hacia atrás' en una economía hacia afuera: Chile, circa 1860-1920", en Cuadernos de Historia, N ${ }^{\circ} 20$, Santiago, 2000, 87-122.

65 $M M M, 1901,183$.

$66 \quad M M M, 1885$, VII. 
Siguiendo esos propósitos, en 1884 fue entregado el crucero Esmeralda, construido en Inglaterra, que llenó un vacío táctico en la escuadra. En palabras del ministro de Marina: "más de una vez se lamentó durante el curso de la guerra la falta de un buque rápido que pudiese a su placer, dar o esquivar el combate, servir de aviso, amenazar convoyes, e introducir el desaliento en los puertos enemigos". La nave tenía 2.800 toneladas de desplazamiento, un andar de 17 millas y poder mecánico aplicado a la maniobra, a la artillería y al manejo de anclas, además de telégrafos y alumbrado eléctrico. Fue la primera nave de su tipo y un importante producto de la industria naval británica ${ }^{67}$.

La compra de armamentos se amplió en 1887, con naves capaces de operar en cualquier condición climática. En ese entonces solo se disponía de dos fragatas blindadas, y la única nave moderna era el crucero Esmeralda, ya que el resto eran naves viejas como el Huáscar, capturado a Perú en 1879 y que no podía navegar en los mares australes. Se contrató con la compañía francesa Forges et Chantiers du Méditerranée, la construcción del acorazado Capitán Prat, con un desplazamiento de 6.769 toneladas, al que se sumaron contratos en Inglaterra y Francia de cazatorpederos, cruceros y destructores ${ }^{68}$. En 1898 se agravó la disputa de límites con Argentina, lo que impulsó la compra de naves (ver tabla 3) hasta llegar a un punto alto en 1902, con el contrato en Inglaterra para construir los acorazados Constitución y Libertad, de 12.000 toneladas cada uno, con una potencia de $25.000 \mathrm{HP}$ y un andar de 21 nudos, que debían ser entregados en 18 meses ${ }^{69}$. En 1903, en pruebas de artillería, el acorazado Constitución lanzó 13,5 toneladas de proyectiles por minuto, siendo considerado el mejor artillado de la época ${ }^{70}$. Pero en mayo de 1902 los gobiernos de Chile y Argentina firmaron los Pactos de Mayo, primera convención sobre limitación de armamentos navales, que estableció el cese de las compras, la disminución de las escuadras y una moratoria de cinco años en la compra de armamento. En diciembre de 1904, la firma de A. Gibbs e Hijos de Londres adquirió para el gobierno británico los dos acorazados, por un valor de 1.800.000 libras esterlinas, y cubrió lo adeudado a las firmas constructoras ${ }^{71}$.

Al momento de la moratoria, el balance de la carrera de armamentos navales era desfavorable, tanto financiera como militarmente para Chile: las compras no habían seguido un fin estratégico y táctico claro, por lo que se adquirió un material heterogéneo (véase tabla 3) sin una infraestructura de muelles, depósitos y arsenales que lo respaldara.

$67 M M M, 1884$, VI, VII

68 "El nuevo blindado para la Marina de Chile", en $R d e M$, tomo VII, No 41, 1888, 397-398; "El Capitán Prat", en RdeM, tomo VIII, N 48, 1889, 534; "Pruebas de la artillería del 'Presidente Pinto"”, en RdeM, tomo XII, No 73, 1892, 605; "Lanzamiento del nuevo crucero 'Ministro Zenteno'”, en RdeM, tomo XX, No 117, 1896, 232; "Lanzamiento de la 'Esmeralda'", en RdeM, tomo XX, No 119,1896 , 431; "Las nuevas construcciones", en RdeM, tomo XXI, No 122, 1896, 229; López, op. cit., 415.

69 "Chile. Compra de buques de combate", en RdeM, tomo XXXII, N ${ }^{\circ} 191,1902,560$.

70 "El acorazado chileno "Constitución", en RdeM, tomo XXXIV, No 201, 1903, 381-382.

71 Octavio Errázuriz y Germán Carrasco, Las relaciones chileno-argentinas durante la presidencia de Riesco, 1901-1906. El arbitraje británico de 1899-1903. Sus aspectos procesales, Santiago, Editorial Andrés Bello, 1968, 111-117; MMM, 1904, XII. 
A esto hay que agregar que se pagaron altos precios por los acorazados Constitución y Libertad, un tercio más de lo normal, por la premura en la entrega, y que la diversidad de naves y aparatos de propulsión incrementaron los costos de mantenimiento. Además de esto, estaban los problemas planteados por los ensayos que hicieron los constructores, tal como ocurrió con el crucero Zenteno, en el cual la cubierta fue dedicada a carbonera, pañoles y municiones, por lo que perdía estabilidad cuando se vaciaba el carbón ${ }^{72}$. Otro problema fue que las armas no se acompañaron de la construcción de depósitos de carbón adecuados, por lo que a las naves se les exigía un gran radio de acción en una costa carente de instalaciones de carga mecanizada. Un ejemplo de esto lo dio en 1900 el crucero Esmeralda, que en el puerto de Coquimbo demoró 22 días en cargar 500 toneladas de carbón con estibadores y marinos, demora fatal en caso de guerra ${ }^{73}$. Finalmente había naves inútiles para las condiciones chilenas, como los cazatorpederos, naves diseñadas en Inglaterra para contrarrestar los torpederos franceses, que en pocas horas podían llevar un ataque, pero que en Chile no eran necesarios, porque no era presumible que llegara un ataque de torpederos desde Perú o el Atlántico, ya que por sus pequeñas dimensiones y capacidad de combustible no podrían soportar las condiciones de un viaje largo en mares agitados ${ }^{74}$.

\section{MAGNITUDES Y COMPLEJIDAD: LAS DIFERENCIAS ENTRE LA ARMADA Y EL EJÉRCITO}

Entre 1854 y 1902 se dio un accidentado camino de aprendizaje y modernización tecnológica, en el que predominó la coyuntura y la improvisación, pero que cambió sustancialmente la composición de los militares, especialmente en la Armada, servicio sobre el cual nos concentraremos. Esta opción de análisis debe destacarse, porque Chile, a través de la Marina de guerra, se incorporó al fenómeno global de la comercialización de armamentos industriales, que en esa época recogían las experiencias de conflictos periféricos. El crucero surgió de la experiencia de guerra naval de Chile contra Perú, en 1879, y el acorazado moderno recogió las lecciones de la guerra ruso-japonesa de 1905, transformándose en un arma fundamental para ganar la guerra y establecer un nuevo tipo de predominio ${ }^{75}$.

También se impuso el predominio de los profesionales y de los técnicos por sobre la tropa ${ }^{76}$. Esto se puede ejemplificar con el incremento que experimentó el personal

72 Rafael Astorga, "Lo que desearíamos que fuese nuestra marina de guerra", en RdeM, tomo XXIX, N ${ }^{\circ} 169,1900,12-14$.

73 Gregorio Santa Cruz, "Faenas de carbón", en RdeM, tomo XXX, No 180, 1901, 619.

74 P. Martínez, "Composición de nuestro material naval: necesidad de un programa de construcción naval para el futuro", en RdeM, tomo XXXI, N $182,1901,143-150$.

75 Michael Howard, La guerra en la historia europea, México, Fondo de Cultura Económica, 1983, 211-215. William McNeill, La búsqueda del poder. Tecnología, fuerzas armadas y sociedad desde el 1000 d.C., México, Siglo XXI, 1989, 292; Alex Roland, "Technology and War: The Historiographical Revolution of the 1980s", en Technology and Culture, Vol. 34, N 1, Chicago, 1993, 118-134.

76 Barton C. Hacker, "Engineering a New Order: Military Institutions, Technical Education, and the Rise of the Industrial State”, en Technology and Culture, Vol. 34, No 1, Chicago, 1993, 12-18. 
técnico dentro del total de las Fuerzas Armadas de los Estados Unidos, entre 1860 y 1945. Durante la Guerra de Secesión (1861-1865) en el bando de la Unión, que tenía un total de 2,2 millones de soldados, el personal técnico y científico correspondía al $0,2 \%$ del total y los mecánicos y personal de reparaciones al 0,1\%. Estas cifras se elevaron a 3,7 y 8,5\% respectivamente durante la Primera Guerra Mundial, para un total de 4,7 millones de hombres ${ }^{77}$. La necesidad de personal calificado en el manejo de la artillería, máquinas, maniobra y mando fue un proceso paralelo al desarrollo de una tecnología militar que combinaba potencia y precisión con habilidades manuales y conocimientos técnicos. Esas calificaciones eran claves, lo que fue demostrado durante la Primera Guerra Mundial, cuando la supremacía de la marina británica varias veces fue cuestionada por la mala puntería de sus artilleros, a pesar de que empleaban complejos tecnológicos como los acorazados Dreadnought ${ }^{78}$.

El armamentismo planteó grandes desafíos laborales, educativos e institucionales, que fueron traspasados a los países compradores, constituyéndose en uno de los más importantes mecanismos de transferencia tecnológica, junto con el ferrocarril y la industrialización ${ }^{79}$.

En Chile, desde la década de 1870 empezó a cambiar la composición del personal naval, al incorporarse las fragatas blindadas Cochrane y Blanco Encalada, que empleaban mecánicos e ingenieros, aunque en pequeña cantidad: en el Cochrane, de una tripulación de 260 personas, 6 eran ingenieros mecánicos, 5 mecánicos y uno herrero. Durante la Guerra del Pacífico fue muy difícil conseguir personal técnico, por lo que se contrataron artilleros, ingenieros y mecánicos extranjeros, británicos en su mayoría, así como obreros de los ferrocarriles chilenos. Una vez terminado el conflicto también fue difícil llenar las plazas, por la competencia de la Marina mercante y de la minería del norte del país ${ }^{80}$.

Por ello los mecánicos e ingenieros adquirieron gran importancia entre $1885 \mathrm{y}$ 1890 en la Armada, mucho más que en el Ejército, cuyo proceso de tecnificación fue más lento y opaco. Esto podemos estimarlo a través de algunas cifras, entre 1866 y 1925 . Un primer aspecto que hay que destacar es que en la estadística chilena se registraba muy poco o nada la existencia de personal técnico en las fuerzas terrestres, a diferencia de lo que ocurría con las fuerzas navales. Como se puede ver en las cifras que presentamos en las tablas 1 y 2, en el Ejército era abrumador el peso de las masas de soldados, con el 93\% del personal en 1881. Para tener un contraste más preciso tomemos el año 1890: en la Armada el personal industrial, técnicos calificados e ingenieros, llegaba al 19,1\% del total, en cambio en el Ejército el $87,1 \%$ del personal eran soldados y el resto oficiales. El porcentaje de tropa iría bajando lentamente al entrar en vigor la ley de servicio militar obligatorio y definirse el cuadro permanente de suboficiales y especialidades.

77 U.S. Department of Commerce. Bureau of the Census, Historical Statistics of the United States. Colonial Times to 1970, Vol. 2, New York, Kraus International Publications, 1989, 1.140.

78 Geoffrey Regan, Historia de la incompetencia militar, Barcelona, Editorial Crítica, 1989, 106.

79 Hacker, "Engineering", op. cit., 8.

$80 \quad M M M, 1883,58-59$; Guillermo Guajardo, "El aprendizaje de la tecnología del ferrocarril en Chile, 1850-1920", en Quipu. Revista Latinoamericana de Historia de las Ciencias y la Tecnología, No 9, México, 1992, 36. 
TABLA 1

PERSONAL TOTAL, TECNO-INDUSTRIAL, TECNO-MILITAR Y DE INGENIEROS DE LA ARMADA DE CHILE, 1866-1925 (AÑOS SELECCIONADOS)

\begin{tabular}{|c|c|c|c|c|c|c|c|}
\hline$\overline{\text { Años }}$ & $\begin{array}{c}1 \\
\text { Personal } \\
\text { total }\end{array}$ & $\begin{array}{c}2 \\
\text { Personal } \\
\text { tecno- } \\
\text { industrial }^{(*)}\end{array}$ & $\begin{array}{c}3 \\
\text { Personal } \\
\text { tecno-militar } \\
(* *)\end{array}$ & $\begin{array}{c}4 \\
\text { Ingenieros } \\
\text { y técnicos } \\
\text { calificados }^{(* * *)}\end{array}$ & $\begin{array}{c}\% \\
\text { del total } \\
\text { considerando } \\
4\end{array}$ & $\begin{array}{c}\% \\
\text { del total } \\
\text { considerando } \\
2 \text { y } 4\end{array}$ & $\begin{array}{c}\% \\
\text { del total } \\
\text { considerando } \\
2,3 \text { y } 4 \\
\end{array}$ \\
\hline 1866 & & & & 32 & & & \\
\hline 1872 & & & & 28 & & & \\
\hline 1873 & & & & 29 & & & \\
\hline 1874 & & & & 31 & & & \\
\hline 1875 & & & & 36 & & & \\
\hline 1883 & & & & & & & \\
\hline 1884 & 2.023 & & & 96 & 4,7 & & \\
\hline 1885 & 2.504 & & & 99 & 3,9 & & \\
\hline 1886 & 2.220 & & & 63 & 2,8 & & \\
\hline 1887 & 2.292 & & & 96 & 4,1 & & \\
\hline 1888 & 1.726 & 199 & & 63 & 3,5 & 15,1 & \\
\hline 1889 & 1.588 & 191 & & 106 & 6,6 & 18,7 & \\
\hline 1890 & 1.589 & 191 & & 114 & 7,1 & 19,1 & \\
\hline 1891 & 1.630 & & & 126 & 7,7 & & \\
\hline 1892 & 2.050 & 363 & & 173 & 8,4 & 26,1 & \\
\hline 1894 & 2.822 & & & 88 & 3,1 & & \\
\hline 1895 & 3.860 & & & 101 & 2,6 & & \\
\hline 1896 & 4.162 & & & 105 & 2,5 & & \\
\hline 1897 & 4.162 & & & 105 & 2,5 & & \\
\hline 1898 & 4.237 & & & 70 & 1,6 & & \\
\hline 1899 & 4.512 & & & 138 & 3,0 & & \\
\hline 1900 & 4.551 & & & 177 & 3,8 & & \\
\hline 1901 & 4.820 & & & 149 & 3,0 & & \\
\hline 1902 & 4.406 & & & 169 & 3,8 & & \\
\hline 1903 & 5.414 & & & 110 & 2,0 & & \\
\hline 1904 & 5.709 & & & 147 & 2,5 & & \\
\hline 1905 & 5.709 & & & 147 & 2,5 & & \\
\hline 1906 & 5.714 & & & 162 & 2,8 & & \\
\hline 1914 & 6.799 & 2.450 & 476 & & & & \\
\hline 1917 & 6.234 & & & 153 & 2,4 & & \\
\hline 1918 & 5.595 & & & 163 & 2,9 & & \\
\hline 1919 & 5.420 & 1.590 & 567 & 157 & 2,8 & 32,2 & 42,6 \\
\hline 1921 & 6.108 & 2.274 & 607 & 164 & 2,6 & 39,9 & 49,8 \\
\hline 1922 & 6.885 & 2.204 & 985 & 171 & 2,4 & 34,4 & 48,8 \\
\hline 1923 & 7.119 & 2.172 & 944 & 164 & 2,3 & 32,8 & 46,0 \\
\hline 1924 & 5.388 & 1.906 & 418 & 166 & 3,0 & 38,4 & 46,2 \\
\hline 1925 & 7.480 & 2.092 & 452 & 158 & 2,1 & 30,0 & 36,1 \\
\hline
\end{tabular}

* Considera el personal de maquinistas, mantenimiento de torpedos, "maestranza de cubierta" de mecánicos y reparaciones. A veces se registraba como "personal especial": obreros ocupados en el Apostadero Naval de Talcahuano y Magallanes, arsenal de marina, armas de guerra y municiones, torpedos y minas, Escuela Naval y Escuela de Aspirantes a Ingenieros.

** Personal que operaba la artillería, torpedos y minas.

*** Ingenieros, técnicos, especialidades de electricidad, máquinas y mecánicos de torpedos (en ciertos años se incluyen los aprendices de ingeniería).

Fuente: Elaboración propia con datos de Chile. Oficina Central de Estadística, Sinopsis estadística y geográfica de la República de Chile, Censo general de la República de Chile y Anuario estadístico de la República de Chile, de los años correspondientes. Las cifras de 1866 a 1875 corresponden a "Dotación de ingenieros de los buques de la Armada de la República que a continuación se expresan, 1866", Archivo Nacional de Chile, Fondo Ministerio de Marina, Vol. 144; "Memoria de la Comandancia General de Marina”, años 1872, 1873, 1874, 1875, Archivo Nacional de Chile, Fondo Ministerio de Marina, Vol. 300. 
TABLA 2

COMPOSICIÓN DEL PERSONAL DEL EJÉRCITO DE CHILE, 1881-1914 (AÑOS SELECCIONADOS)

\begin{tabular}{lccccc}
\hline Años & Personal total & Oficiales & $\begin{array}{c}\text { Cuadro } \\
\text { permanente }\end{array}$ & $\begin{array}{c}\text { Tropa y } \\
\text { conscriptos }\end{array}$ & $\begin{array}{c}\text { \% de tropa en el } \\
\text { personal total }\end{array}$ \\
\hline 1881 & 13.351 & 915 & & 12.436 & 93,1 \\
1885 & 8.070 & 970 & & 7.100 & 87,9 \\
1890 & 7.323 & 938 & & 6.385 & 87,1 \\
1895 & 9.623 & 623 & & 9.000 & 93,5 \\
1900 & 18.248 & 863 & 5.885 & 11.500 & 63,0 \\
1901 & 15.729 & 550 & 5.765 & 9.414 & 59,8 \\
1902 & 15.623 & 915 & 5.500 & 9.208 & 58,9 \\
1903 & 12.557 & 915 & 5.500 & 6.142 & 48,9 \\
1914 & 18.604 & 760 & 8.044 & 9.800 & 52,6 \\
\hline
\end{tabular}

Fuente: Elaboración propia con datos de Chile. Oficina Central de Estadística, Sinopsis estadística y geográfica de la República de Chile, Censo general de la República de Chile y Anuario estadístico de la República de Chile, de los años correspondientes

La Armada adquirió tempranamente el perfil laboral de una fuerza moderna, al tener cerca de un tercio de su personal con calificaciones técnicas y productivas, tanto así que hacia 1918 por sí sola aportaba entre el 13 y el $14 \%$ del personal técnico de las Fuerzas Armadas. Esto cuestiona la idea de que la "prusianización" del Ejército, iniciada en la segunda mitad de la década de 1880, lo modernizó en el sentido de darle más tecnificación; es cierto que el arma central en las fuerzas terrestres es la infantería, pero ya desde esos años la artillería, telegrafía, ingenieros de puentes, ferrocarriles y el soporte de industrias y armas técnicas también eran importantes. El atraso en esas dimensiones también explica la adhesión de algunos sectores de esa institución a proyectos industrialistas, para superar su condición de fuerza preindustrial.

Las diferencias residían en la composición de las armas empleadas por uno y otro servicio. Tal como se anota en la tabla 3, la Armada experimentó un crecimiento vertiginoso en cantidad, variedad y potencia de sus naves de guerra, pasando de 15 naves en 1880 a 45 unidades en 1905.

Ese proceso se acompañó de cambios radicales en la sofisticación y diversidad tecnológica, lo que se expresó en el incremento de la potencia-medida en HP- de la escuadra, donde es posible encontrar hechos sorprendentes y hasta ahora desconocidos.

En la tabla 4 hemos reunido datos del peso y potencia de la escuadra entre 1876 y 1923, sin considerar los HP de las instalaciones de tierra, constituidas por 
talleres, arsenales y astilleros, pues solo disponemos de los datos de lo que flotaba. En peso, hasta 1901 la flota se incrementó cerca de siete veces, pero en más de 24 si se considera la potencia, razón por la cual la energía per cápita del personal encargado del funcionamiento y mantenimiento de las máquinas y estructuras de las naves, evolucionó desde una asignación de 211 HP per cápita en 1878 -cifra muy alta por falta de personal- a 182,5 HP después de la Guerra del Pacífico, 821,6 HP en 1900 y 1.733 ,1 en 1903. Incremento que fue más balanceado en el peso, por la mejor relación de peso por HP que tenían las naves desde fines de la década de 1890 .

TABLA 3

NAVES DE LA ARMADA DE CHILE, 1880-1905

\begin{tabular}{lcccccc}
\hline Tipo de nave & 1880 & 1885 & 1890 & 1895 & 1900 & 1905 \\
\hline Acorazado & 0 & 0 & 0 & 1 & 2 & 2 \\
Crucero & 0 & 1 & 1 & 3 & 6 & 5 \\
Corbeta & 4 & 2 & 3 & 1 & 1 & 1 \\
Cañonero & 2 & 2 & 2 & 2 & 2 & 2 \\
Cazatorpedero & 0 & 0 & 2 & 2 & 3 & 3 \\
Destructor & 0 & 0 & 0 & 0 & 4 & 7 \\
Fragata blindada & 2 & 2 & 2 & 1 & 1 & 1 \\
Torpedero & 0 & 9 & 10 & 10 & 14 & 14 \\
Monitor & 1 & 1 & 1 & 1 & 1 & 1 \\
Naves de apoyo (buque-escuela, & & 7 & 3 & 8 & 10 & 10 \\
escampavías, vapores y transportes) & 6 & 24 & 24 & 29 & 44 & 45 \\
Total & 15 & & & & & \\
\hline
\end{tabular}

Fuente. Elaboración propia con datos de Chile. Oficina Central de Estadística, Sinopsis estadística y geográfica de la República de Chile, Censo general de la República de Chile y Anuario estadístico de la República de Chile, de los años correspondientes.

Si comparamos la planta de personal de la Armada con la de otras actividades, surgen otros hechos importantes. En la tabla 5 hemos confrontado su personal técnico con el empleado en la industria manufacturera (excluyendo niños y mujeres), los operarios de los talleres de EFE y los de fundiciones y metalurgia del cobre. Era un personal pequeño, pero tenía una muy alta tasa de crecimiento, el cual para 1914 alcanzaba las dimensiones del que se empleaba en los ferrocarriles y el cobre: $7 \%$ con respecto al de manufacturas, 38\% al de los ferrocarriles y $50 \%$ al del cobre. En la Armada sí había bases sociales con capacidad de respaldar un posible proyecto desarrollista-estatista, sin embargo ello no ocurrió. 
TABLA 4

TONELADAS Y POTENCIA DE LA ESCUADRA DE LA ARMADA DE CHILE, 1876-1923 (AÑOS SELECCIONADOS)

\begin{tabular}{|c|c|c|c|c|c|}
\hline Años & $\begin{array}{l}\text { Toneladas } \\
\text { de toda } \\
\text { la escuadra }\end{array}$ & $\begin{array}{l}\text { HP (caballos } \\
\text { de fuerza) } \\
\text { de la toda } \\
\text { la escuadra }\end{array}$ & HP por tonelada & $\begin{array}{l}\text { HP por personal } \\
\text { de ingenieros } \\
\text { y técnicos } \\
\text { calificados } \\
\text { (datos } \\
\text { columna } 4, \\
\text { Tabla 1) }\end{array}$ & $\begin{array}{c}\text { Toneladas } \\
\text { por personal } \\
\text { tecno } \\
\text { industrial } \\
\text { (datos } \\
\text { columna 2, } \\
\text { Tabla1) }\end{array}$ \\
\hline 1876 & 10.095 & 7.630 & 0,7 & 211,9 & \\
\hline 1879 & 13.537 & 9.664 & 0,7 & & \\
\hline 1882 & 13.124 & 13.590 & 1,0 & & \\
\hline 1884 & 16.853 & 17.520 & 1,0 & 182,5 & \\
\hline 1888 & 12.228 & & & & 61,4 \\
\hline 1889 & 12.257 & & & & 64,1 \\
\hline 1890 & 13.665 & 20.653 & 1,5 & 181,1 & 71,5 \\
\hline 1891 & 17.310 & 27.873 & 1,6 & 221,2 & \\
\hline 1892 & & & & & 47,6 \\
\hline 1893 & & 39.873 & & 230,4 & \\
\hline 1894 & & 49.373 & & 561,0 & \\
\hline 1895 & 33.435 & 65.010 & 1,9 & 643,6 & \\
\hline 1900 & 55.391 & 145.433 & 2,6 & 821,6 & \\
\hline 1901 & 67.673 & 173.303 & 2,5 & $1.163,1$ & \\
\hline 1902 & 72.173 & 189.053 & 2,6 & $1.118,6$ & \\
\hline 1903 & 73.138 & 190.646 & 2,6 & $1.733,1$ & \\
\hline 1919 & 101.055 & & & & 63,5 \\
\hline 1921 & 132.113 & & & & 58,0 \\
\hline 1923 & 133.531 & & & & 61,4 \\
\hline
\end{tabular}

Fuente: Elaboración propia con datos de Chile. Oficina Central de Estadística, Sinopsis estadística y geográfica de la República de Chile, Censo general de la República de Chile y Anuario estadístico de la República de Chile, de los años correspondientes.

Finalmente, es en la energía donde encontramos una diferencia absoluta. En la tabla 6 hemos comparado los HP de la escuadra con los de algunas actividades. Resulta sorprendente que la potencia alcanzada por la Armada en 1900 no haya sido superada en 17 años por toda la industria, como también que, en 1876, las pocas naves de vapor que poseía generaran más HP que las máquinas y locomotoras empleadas en la extracción de carbón. Pero la comparación definitiva es con la producción de cobre, que desde 1915 empezó a ser una importante exportación, por las fuertes inversiones estadounidenses, y que más tarde asumió el papel que cumplió el salitre en el comercio exterior. A pesar de esto, recién en 1925 el cobre alcanzó una cifra de generación de HP como la lograda por la Marina de guerra 24 años antes. 
TABLA 5

COMPARACIÓN DEL TAMAÑO DEL PERSONAL TECNOINDUSTRIAL DE LA ARMADA CON EL DE OTROS SECTORES LABORALES, 1888-1925 (AÑOS SELECCIONADOS)

\begin{tabular}{lcccc}
\hline Años & $\begin{array}{c}\text { Personal tecno- } \\
\text { industrial de la } \\
\text { Armada (columna 2) }\end{array}$ & $\begin{array}{c}\text { Operarios de la } \\
\text { industria } \\
\text { manufacturera }\end{array}$ & $\begin{array}{c}\text { Personal de } \\
\text { de talleres y } \\
\text { tracción de los } \\
\text { Ferrocarriles } \\
\text { del Estado }\end{array}$ & $\begin{array}{c}\text { Operarios de } \\
\text { fundiciones y } \\
\text { metalurgia } \\
\text { del cobre }\end{array}$ \\
\hline 1888 & 199 & 2.098 & \\
1889 & 191 & & 2.457 & \\
1890 & 191 & & 2.823 & \\
1892 & 363 & $31.093^{*}$ & 6.425 & 5.897 \\
1914 & 2.450 & 40.438 & & 5.959 \\
1919 & 1.590 & 40.954 & & 12.624 \\
1921 & 2.274 & 43.298 & & 12.003 \\
1922 & 2.204 & 46.179 & & 12.453 \\
1923 & 2.172 & 48.676 & & 16.179 \\
1924 & 1.906 & 48.845 & 14.776 & \\
1925 & 2.092 & & & \\
\hline
\end{tabular}

* El dato corresponde a 1915 .

Fuente: Elaboración propia con datos de Chile. Oficina Central de Estadística, Sinopsis estadística y geográfica de la República de Chile, Censo general de la República de Chile y Anuario estadístico de la República de Chile, de los años correspondientes.

Las dimensiones cuantitativas y cualitativas nos indican la magnitud del desequilibrio entre el discurso y la realidad de una y otra rama militar, como también de la historiografía de cada una. A su vez, nos indican que el Estado chileno contribuyó a la mecanización de la economía, invirtiendo en locomotoras y acorazados para movilizar factores y defender el espacio económico, para lo cual debió contar con un abanico de proveedores internacionales de tecnología y aprendizajes, uno de los cuales, Alemania, que había sido escogido por el Ejército, para 1918 estaba derrotado, razón por la cual debió mirar más hacia el mercado interno, lo cual, como veremos, no había buscado con el mismo interés antes de 1914. La Armada en cambio quedó en el bando ganador, con Gran Bretaña, y la tecnocracia pudo saltar de Bélgica hacia una potencia industrial en ascenso, Estados Unidos. Esto aporta bases más sólidas para explicar las conductas de los militares en el plano tecnológico, económico y político. 
TABLA 6

COMPARACIÓN DE LA POTENCIA DE LOS BARCOS DE LA ESCUADRA, EN HP, CON LA DE ALGUNOS SECTORES DE LA ECONOMÍA CHILENA, 1876-1925 (AÑOS SELECCIONADOS)

\begin{tabular}{|c|c|c|c|c|}
\hline Años & $\begin{array}{l}\text { HP (caballos de } \\
\text { de fuerza) de la } \\
\text { toda la escuadra }\end{array}$ & $\begin{array}{l}\text { HP de toda la } \\
\text { industria } \\
\text { manufacturera }\end{array}$ & $\begin{array}{l}\text { HP de las compañías } \\
\text { carboníferas }\end{array}$ & $\begin{array}{l}\text { HP de la maquinaria } \\
\text { de fundiciones y } \\
\text { metalurgia del cobre }\end{array}$ \\
\hline 1876 & 7.630 & & $4.195^{*}$ & \\
\hline 1879 & 9.664 & & & \\
\hline 1882 & 13.590 & & & \\
\hline 1884 & 17.520 & & & \\
\hline 1885 & & & 1.416 & \\
\hline 1890 & 20.653 & & & \\
\hline 1891 & 27.873 & & & \\
\hline 1893 & 39.873 & & & \\
\hline 1894 & 49.373 & & & \\
\hline 1895 & 65.010 & & & \\
\hline 1900 & 145.433 & & & \\
\hline 1901 & 173.303 & & & \\
\hline 1902 & 189.053 & & & \\
\hline 1903 & 190.646 & & & \\
\hline 1915 & & 115.252 & & 70.733 \\
\hline 1916 & & 130.477 & & 88.179 \\
\hline 1917 & & 146.943 & & 89.727 \\
\hline 1918 & & 167.881 & & 87.833 \\
\hline 1919 & & 169.942 & & 127.060 \\
\hline 1920 & & 241.196 & & 128.457 \\
\hline 1925 & & 301.580 & & 175.006 \\
\hline
\end{tabular}

* El dato corresponde a 1875 .

Fuente: Elaboración propia con datos de Chile. Oficina Central de Estadística, Sinopsis estadística y geográfica de la República de Chile, Censo general de la República de Chile y Anuario estadístico de la República de Chile, de los años correspondientes.

\section{CALIFICACIÓN TÉCNICA Y MIGRACIÓN INDUSTRIAL EN LA ARMADA}

La presión para formar y calificar personal se hizo imperiosa desde 1885 , cuando el cuerpo de ingenieros navales empezó a experimentar una crisis por la insuficiencia de sus conocimientos sobre las nuevas naves y equipos militares. Para ese entonces, la mayoría se había formado en la misma Marina, "sobre la marcha", y los menos en la EAO. En 1885 el ministro de Marina planteó formar aprendices de ingeniero con alumnos de la EAO, que se entrenarían durante dos años en los talleres de EFE, en Valparaíso, y luego pasarían a un buque escuela y rendirían un 
examen ${ }^{81}$. El proyecto se llevó a cabo después de la guerra civil, por el interés que tuvo la Armada: en 1891 se creó en la EAO un curso destinado a formar exclusivamente mecánicos e ingenieros navales ${ }^{82}$.

La presión se incrementó por la incorporación de nuevos tipos de armas, como el destructor adquirido en 1896, que descartó el empleo de marineros reclutados en los campos. Las naves eran de pequeño tamaño, con cascos livianos para ser veloces y máquinas ligeras, y requerían poco personal, en su mayoría calificado. Para un oficial naval chileno "a bordo de los destroyers, debe haber solo gente de trabajo y no convertirse el buque en escuela de instrucción"83.

A su vez, en el manejo de las armas faltaba preparar especialidades de artilleros y torpedistas. A partir de la guerra Hispanoamericana (1898) y Ruso-Japonesa (1904-1905), se modificó significativamente el tiro de artillería, al basarse más en cálculos, instrumentos y personal preparado, área en que la Marina chilena tenía graves deficiencias. Esto era evidente en el tiro de torpedos, ya que en la Armada no se anotaban las prácticas para calcular el desvío por el movimiento del buque, ni se elaboraban tablas para lograr una buena puntería ${ }^{84}$.

Para 1902, el crucero Esmeralda habían lanzado en marcha solo un torpedo en el año ${ }^{85}$, razón por la cual eran frecuentes los malos resultados, tal como ocurrió en 1905, cuando en las maniobras navales llevadas a cabo en el puerto de Antofagasta, el destructor $O$ 'Brien falló el lanzamiento por defectos del material del tubo y por el "nerviosismo" del personal, que se justificó por la presencia del Presidente de la República; otro disparo falló porque el personal accionó el control eléctrico antes de tiempo ${ }^{86}$. Estos problemas también se debían a la inactividad de la flota por el bajo presupuesto asignado para operaciones, lo que afectó la formación. Esto lo anotó, en 1909, el capitán Luis Langlois, director de la Escuela de Artillería de la Armada, al referirse a las dificultades para formar artilleros: "obtener esta precisión, educar sus nervios, dotarlos de agilidad para mover su cañón y contrarrestar el balance y guiñadas, es lo que se requiere y estas cualidades solo se desarrollan con una constante práctica de tiro en la mar" 87 .

Para solucionar esos problemas, en 1896 se creó la Escuela de Aspirantes a Ingenieros Mecánicos (EIM), con la misión de formar oficiales técnicos capaces de operar y reparar las máquinas marinas, que abrió sus cursos con 25 alumnos, aprovechando la instrucción que se veía dando en la EAO desde 1891. Otro de sus objetivos era acabar con la dependencia del personal extranjero a contrata, que era escaso y caro; para lo cual una medida inmediata consistió en contratar obreros egresados de la EAO, a quienes se envió a practicar a talleres europeos. Los estudios duraban cuatro años, con cursos de matemáticas, humanidades, mecánica,

81 MMM, 1885, XXXIII y 7-10.

82 Guajardo, "El aprendizaje", op. cit., 28-29.

83 "Las nuevas construcciones", en RdeM, tomo XXI, N ${ }^{\circ} 122,1896,239$

84 MMM, 1897, 54-55; MMM, 1901, 7.

85 J. Walton, "Nuestro material de torpedos", en RdeM, tomo XXXIII, Nº 196, 1902, 367.

86 Idem.

87 "La escuadrilla de torpederos. Parte del capitán Garín", en RdeM, tomo XXXVIII, No 225, 1905, 319-320. 
máquinas, electricidad y trabajos prácticos. Para 1900 la EIM contaba con 55 alumnos y enfrentaba problemas por los deficientes conocimientos de estos y la falta de libros, de instalaciones y talleres propios, ya que realizaba sus actividades en los Arsenales de Marina. A pesar de las dificultades, en 1901 se graduaron 15 oficiales, que fueron enviados a prácticas en fábricas británicas de armamentos ${ }^{88}$.

Los primeros graduados que se enviaron a Gran Bretaña debieron enfrentar condiciones muy adversas. Estaban casi en la miseria, por la escasa pensión que recibían del gobierno, y cubrían largas jornadas de trabajo; eran una minoría pobre frente a las mejores condiciones y número del personal que Argentina tenía en el mismo lugar. No obstante, con la práctica adquirida en 1902, volvieron a Chile haciéndose cargo de las maquinarias del destroyer Thompson ${ }^{89}$.

Una vez llegados al país, las dificultades para los ingenieros navales no terminaron, porque quedaron en desventaja frente a los oficiales ejecutivos o de guerra, que tenían el comando de las naves. Sin embargo, la urgente necesidad de personal técnico incrementó su número y para 1904 ya había 118 oficiales ingenieros que, sumados a 47 contratados, constituían $30 \%$ de los oficiales de la Armada ${ }^{90}$. Para 1909 se habían graduado 110 alumnos, que, dada su calificación tecnológica, empezaban a desertar hacia las actividades privadas, ya que 40 de ellos habían ido a trabajar a firmas industriales ${ }^{91}$. En ese entonces el programa de estudios de la EIM se había extendido a cinco años, con nuevos cursos, como el de turbinas, combustión interna, máquinas hidráulicas y radiotelegrafía, y con un mayor número de horas de trabajos de taller para una total de 127 alumnos ${ }^{92}$. A pesar de los esfuerzos, hacia 1910 el personal extranjero a contrata seguía ocupando los puestos más altos.

Esto último aumentó el descontento de los oficiales ingenieros, que también se dirigió al ámbito civil y académico, que no les ofrecía oportunidades de mayor desarrollo profesional. En 1910, un anónimo oficial, a través de la Revista de Marina, criticó a la Universidad de Chile, por no preocuparse de formar ingenieros mecánicos y constructores navales, ni pensar que el futuro estaba en la industria y no en la minería. Pero al interior de la Armada, un mayor número de ingenieros cuestionaba a los oficiales de guerra, ya que sus programas no se habían unificado, a diferencia de la Armada británica, que era el modelo ideal que seguía la Marina de guerra chilena. Para 1915 todavía se consideraba difícil lograrlo, por la reforma de los programas de formación y también porque el personal subalterno de maquinistas y mecánicos era insuficiente ${ }^{93}$.

88 MMM, 1897, 17; MMM, 1900, X.

89 "Los aspirantes a ingenieros en Europa", en RdeM, tomo XXX, N ${ }^{\circ} 180,1901,662-663$; Araucano, "El primer ensayo de los aspirantes a ingenieros", en RdeM, tomo XXXIV, No 198, 1902, 637.

90 "Personal al 31 de diciembre de 1904", en $M M M, 1905,120-121$; J.A.G., "Sobre el personal de máquinas de la Armada", en RdeM, tomo XXXV, No 209, 1903, 602.

91 "Escuela de Ingenieros Mecánicos de la Armada", en RdeM, tomo XLVI, N 272, 1909, 118; MMM, 1909, 88 .

92 Chile. Armada de Chile, La Escuela de Ingenieros de la Armada en 1910, Valparaíso, Taller Tipográfico de la Escuela, 1910, 9-16.

93 Orompello, "El cuerpo de ingenieros de la Armada", en RdeM, tomo XLIX, N 293, 1910, 418-420; "Encuesta del director de la Escuela de Ingenieros, capitán de fragata Sr. Arturo Acevedo", en RdeM, tomo LIX, No $347,1915,423$. 
Después de 1918, debido a la disminución en la compra de naves y también a que la industria no absorbía a muchos de los graduados de la EIM, el éxito de este programa era cuestionado dentro de la Armada. En 1922, algunos sectores de la institución consideraban que 170 oficiales ingenieros era un número excesivo y que había una "crisis de crecimiento" 94 . En el marco de las intervenciones de los militares en política, en 1927, la EIM fue absorbida por la Escuela Naval, unificándose la formación de los oficiales ejecutivos e ingenieros, artilleros de costa e infantes de Marina, contadores y de abastecimiento, de Marina mercante, de puente y de máquinas, oficiales de litoral y de reserva naval. El alto mando prefirió disciplinar las tendencias industriales que cuestionaban la cadena de mando, lógica similar a la que aplicó para moderar al Ejército.

\section{PROBLEMAS DE ORGANIZACIÓN Y DE EQUIPO FRENTE A LOS DESAFíos ESTRATÉGICOS}

Desde 1905 se presentaron nuevas amenazas para la defensa del país, debido a la presencia naval de Estados Unidos en el Pacífico y el rearme de Argentina, que hacían necesaria una nueva escuadra para cubrir varias hipótesis de guerra. Pero la pérdida de la supremacía naval de Chile en Sudamérica era evidente, y las dificultades económicas y políticas impedían retomar la carrera de armamentos. En 1894 Chile ocupaba el primer lugar de potencia marítima en la región, pero para 1906 había pasado a segundo lugar y estaba en tránsito al tercero, por el incremento de la Armada brasileña, en tanto que Perú había adquirido dos cruceros, en un momento en que todavía no se definían con Chile los límites de Tacna y Arica, y Argentina compraba siguiendo las experiencias de sus oficiales, que estuvieron en naves japonesas durante la guerra con Rusia ${ }^{95}$.

En el Ejército la situación era parecida. En 1906 su reorganización aumentó el número de unidades, pero disminuyó el número de efectivos e hizo dependiente directamente del ministro de Guerra la inspección general del Ejército, el Estado Mayor General, los comandos de divisiones, la dirección de material de guerra, los abastecimientos de división y los establecimientos militares ${ }^{96}$. Así, se diluyó el mando centralizado, por lo que cada comandante podía relacionarse directamente con el Ministro, rompiendo la disciplina, situación agravada por los constantes cambios de gabinete.

94 "La crisis de crecimiento del escalafón de ingenieros", en RdeM, tomo LXVII, N 890, 1922, 1698-1700.

95 “¿En qué ha quedado la proyectada reconstrucción de nuestra armada?”, en RdeM, tomo XL, No 236, 1906, 989; "La reconstrucción de la escuadra", en RdeM, tomo XXXIX, No 229, 1905, 3-4; "Los armamentos navales en Sudamérica", en RdeM, tomo XLI, No 244, 1906, 337-339.

96 José Miguel Piuzzi, "Los militares en la sociedad chilena, 1891-1970. Relaciones civilesmilitares e integración social", Tesis Doctor en Sociología, Universidad Pontificia de Salamanca, 1993, Vol. 2, 613. 


\section{¿TRENES O ACORAZADOS? UNA DISPUTA INÚTIL}

En ese contexto de crisis, se dieron fricciones entre las mismas Fuerzas Armadas, como ocurrió con la disputa entre la Armada y el Ejército, por la construcción de un ferrocarril hacia el norte del país y la adquisición de acorazados entre 1908 y 1910 .

Frente al debilitamiento de la Armada, el Ejército empezó a apoyar la construcción de una línea férrea hacia el norte, por el interior del territorio, para que no fuera atacada desde el mar. El proyecto había surgido durante el gobierno de Domingo Santa María (1881-86) ${ }^{97}$, pero debió esperar hasta 1908 para que se le diera impulso y, a medida que avanzó, empezó a ventilarse la existencia de una disputa entre estas dos ramas. En 1909 aparecieron en la prensa opiniones de que no era indispensable una Marina de guerra y que era suficiente con tener un ejército bien organizado, con facilidades de transporte por ferrocarril y artillería de costa ${ }^{98}$. En 1910 un anónimo oficial del Estado Mayor del Ejército escribió en el principal periódico nacional, El Mercurio, de Santiago, que la escuadra era innecesaria, proponiendo rebajar en varios millones el presupuesto de la Armada e incrementar el del Ejercito ${ }^{99}$. La disputa sobre acorazados y ferrocarriles no trascendió, pero indicó las distancias que había entre los servicios armados.

En ese mismo año, el gobierno suscribió contratos para construir fortificaciones y puertos y comprar 6 destructores, 2 submarinos y 2 acorazados de gran tamaño, del tipo Dreadnought. En 1912 se firmó el contrato con Armstrong \& Co. de Inglaterra, para construir los acorazados Almirante Latorre y Almirante Cochrane; sin embargo en 1914, al estallar la Primera Guerra, el gobierno inglés confiscó las naves y el Almirante Latorre fue empleado con el nombre de Canada, después de lo cual fue devuelto. En 1916 el gobierno inglés compensó a Chile con 5 submarinos por la incautación del Latorre y la compra del Cochrane, que en 1918 fue rebautizado como Eagle ${ }^{100}$.

La Primera Guerra Mundial dejó varias lecciones, que en los años siguientes no fueron muy bien asumidas. Estas fueron expuestas en Chile por Hans Von Kiesling, oficial alemán contratado en 1909 como instructor del Ejército, quien sirvió en el frente occidental y retornó a Chile como profesor de la Academia de Guerra. Kiesling anotó que en Chile la escuadra sería decisiva para defender la costa de desembarcos, razón por la cual descartó el empleo del ferrocarril: "la flota tendría que acompañar al Ejército de Operaciones en su movimiento al norte, para que pueda proceder libremente. Esta tarea será resuelta solo por la escuadra de naves de combate, compuesta de acorazados poderosos, superior en número y en fuerza a

\footnotetext{
97 Marín Vicuña, Los ferrocarriles, op. cit., 179.

98 "La marina de guerra es indispensable en la defensa militar del país", en RdeM, tomo XLVI, $\mathrm{N}^{\mathrm{o}} 271,1909,90$.

99 "Reportaje inoportuno", en RdeM, tomo XLIX, N² 293, 1910, 359-360.

100 "Estado Mayor general de la Marina", en RdeM, tomo L, No 298, 1911, 253; MMM, 1912, VII; $M M M, 1918,10 ; M M M, 1919,71$.
} 
la escuadra enemiga"101. Dicho conflicto puso en evidencia la vulnerabilidad del aparato militar chileno, generando algunas respuestas que iban más allá de sus cuarteles.

\section{PODER MILITAR Y ECONOMÍA NACIONAL}

La Primera Guerra Mundial y la movilización de las economías demostraron que la guerra era un problema de recursos reales, de fuerza de trabajo, de materias primas y de capacidad de producción. Para Chile, el conflicto significó la pérdida de mercados, restricciones a la navegación, cesantía y aumento del precio del nitrato, pero también cambió la relación de los militares con el gobierno, ya que se los consultó sobre los aspectos económicos de la defensa. En abril de 1917, el Presidente de la República nombró una comisión de oficiales de la Armada, el Ejército y asesores civiles, a fin de informar sobre la organización industrial del país para la defensa nacional. En 1918 la comisión estableció que era posible fabricar, con materias primas nacionales, acero, proyectiles y pólvoras tanto para usos mineros como militares. Para los proyectiles se necesitaba una planta completa, cuyo proveedor sería Estados Unidos, y a un alto costo, razón por la cual la Armada opinó que las fábricas de armamentos debían ser estatales, para asegurar calidad y bajo precio ${ }^{102}$. Los resultados de esa iniciativa civil y gubernamental llegaron a la luz pública y el director de la Revista de Marina, el capitán de corbeta retirado A. Asmussen, opinó que debían llevarse a cabo los planes de la comisión y ampliar la capacidad de los talleres de la Armada y del Ejército, para "marchar juntos" en producción y proteger la industria vinculada a la defensa ${ }^{103}$; para un oficial naval activo, B. Barros Merino, era necesario "convertirnos en industriales y productores [...] que nos liberten de la tutela extranjera" 104 .

En el caso del Ejército, la Primera Guerra fue determinante para que este pensara en la autonomía industrial, lo que expresó en 1917 el coronel Mariano Navarrete, director de la Academia de Guerra, en el sentido de que la defensa nacional requería el empleo "inteligente y acertado de todos los recursos de un país y la implantación de industrias [...] preparadas para suministrar en caso de guerra todo lo que las Fuerzas Armadas necesiten para mantener su eficiencia". Las necesidades militares servirían para instalar fábricas estatales, estimular la industria privada, garantizar la inversión y coordinar la economía, mediante un departamento de

101 Hans Von Kiesling, "Las experiencias de la guerra mundial y su importancia para el Ejército de Chile" [1924], en Chile. Ejército de Chile. Academia de Guerra, Cuaderno de Difusión. [Número temático] El pensamiento de estado mayor en el tiempo. Documentos y artículos, 1886-1933, Santiago, Academia de Guerra, 1999, 104-105.

102 "Contribución al aprovechamiento de la industria nacional por la Armada y el Ejército (Editorial)", en RdeM, tomo LXIII, No 363, 1918, 1-4 y 10-11.

103 A. Asmussen, "La organización industrial del país con relación a la defensa nacional", en RdeM, tomo LXIII, No $367,1918,457-458$.

104 B. Barros Merino, "Reconstruyamos en el país nuestros destructores y vipers (necesidad de proteger nuestros astilleros)", en RdeM, tomo LXV, No 376, 1920, 235. 
movilización civil e industrial del Ministerio de Guerra ${ }^{105}$. Ejemplos tomados de la experiencia alemana, que desde 1916 coordinaba industrias a través del comando supremo.

\section{EL FUEGO AMIGO DEL ALTO MANDO A FAVOR DE LA INDUSTRIA CIVIL}

Recogiendo las experiencias de la guerra europea, la primitiva Fábrica de Cartuchos fue transformada en el complejo FAMAE, que para 1921 fundía y manufacturaba cobre y bronce, como también fabricaba maquinarias, partes y piezas de ingeniería.

El problema es que, desde esos años, su producción empezó a competir con las empresas de ingeniería, mecánica y de fundición que eran defendidas por la SOFOFA, entidad que pidió al gobierno la restricción de las operaciones de FAMAE ${ }^{106}$. Frente a ello, el Ministerio de Guerra integró una comisión con miembros de la SOFOFA, de la Sociedad Nacional de Agricultura, del consejo de EFE y el director de FAMAE, para elaborar un proyecto que alejara "el peligro de la competencia que ese establecimiento fiscal pueda hacer a la industria particular"107. La comisión recomendó, en 1923, darle a FAMAE personalidad jurídica y moderar su carácter industrial con un "consejo de vigilancia" de siete miembros, de los cuales tres representarían intereses privados, tres a las Fuerzas Armadas y uno a EFE, para "Informar al Gobierno sobre la capacidad de la industria privada para abastecer al Ejército de los artículos que le fuesen necesarios en caso de guerra, y sobre los medios de obtener su completa adaptación y dedicación eventual a fines béli$\cos { }^{108}$. El ministro de Guerra, el general Altamirano, justificó la inclusión de los empresarios porque "supone que los miembros de dichas Sociedades están más capacitados que los militares para indicar las clases de máquinas y herramientas que se necesitan en el país" 109 .

Este fuego amigo manifestó el carácter moderador del alto mando del Ejército hacia las propuestas de los oficiales de las unidades productivas, coincidiendo en esto plenamente con el alto mando naval, que hizo lo mismo con sus ingenieros, lo cual cuestiona la idea de que las posturas industrialistas eran institucionales.

En 1924, la discusión sobre FAMAE quedó interrumpida en el Congreso por el inicio de las intervenciones militares, que desataron un proceso que primero obligó al Legislativo a aprobar leyes sociales postergadas, más tarde condujo a la

105 Mariano Navarrete, "La defensa nacional" [1917], en Chile. Ejército de Chile. Academia de Guerra, op. cit., 75 y 84-85.

106 Pedro L. González, "Las industrias fiscales (Editorial)", en Boletín de la Sociedad de Fomento Fabril, tomo XXXVIII., Santiago, 1921, 405-406; Jorge Boonen Rivera, Participación del Ejército en el desarrollo y progreso del país, Santiago, Imprenta y Encuadernación El Globo, 1917.

107 "Fábricas y Maestranzas del Ejército (Actas de las sesiones del Consejo Directivo)", en Boletín de la Sociedad de Fomento Fabril, tomo XXXVIII, Santiago, 1921, 454.

108 Chile. Cámara de Senadores, Boletín de las Sesiones Ordinarias correspondiente a 1923, 696-697.

109 Ibid., 699. 
renuncia del presidente Arturo Alessandri y en 1925 a la promulgación de la nueva Constitución ${ }^{110}$.

No obstante, durante el período de los movimientos militares, la FAMAE incrementó su capacidad industrial y para 1931 presentó una propuesta para construir carros de carga para EFE, con lo cual nuevamente la SOFOFA reclamó al gobierno por la competencia "ruinosa para la industria privada", advirtiendo que la industria estatal solo debía elaborar artículos que no se fabricaban en el país y manufacturar metales para otras industrias ${ }^{111}$. La mayor competitividad del aparato militar se debía a que, después de 1924, el Ejército llevó a cabo una reestructuración a favor de su capacidad técnica e industrial, al crear la Academia Técnica Militar, cuyas actividades se iniciaron al interior de FAMAE. Para 1933, y en el marco de las consecuencias de la Depresión, la FAMAE, además de ser la sede formadora de ingenieros militares, sustituía importaciones, ofrecía una amplia gama de productos y servicios e incursionaba en la fabricación de maquinarias, herramientas para la industria, agricultura, municiones para armas pequeñas y refacciones para automóviles ${ }^{112}$

Distinta fue la actitud de la SOFOFA con los astilleros de la Armada, que no presentaban competencia para los empresarios, debido al escaso desarrollo de la construcción naval. Por ello, en 1920 la Asamblea de Industriales recomendó al gobierno ampliar y completar los astilleros del Apostadero Naval de Talcahuano (ANT), para mantener en buen estado la escuadra de guerra y construir vapores mercantes ${ }^{113}$, razón por la cual no reclamó cuando el Apostadero reparó naves no militares, ingresos que hacia 1924 cubrían parte de su operación ${ }^{114}$.

\section{UN PROYECTO DESCARRILADO: \\ EL INTENTO DEL EJÉRCITO POR CONTROLAR LOS FERROCARRILES}

Para ese entonces, uno de los proyectos del Ejército que mayor oposición civil generó fue el intento por controlar los ferrocarriles. El Ejército, desde 1906, contaba con el "Batallón de Ferrocarrileros", unidad especializada en la instrucción militar de fogoneros y maquinistas, que también cumplía labores de construcción en la línea de Santiago al puerto de San Antonio ${ }^{115}$. En 1919, el jefe del Estado Mayor del Ejército planteó al Consejo de Ferrocarriles la inclusión de maquinistas

110 Chile. Cámara de Diputados, Boletín de las Sesiones Extraordinarias correspondiente a 19231924, 343; Blakemore, "Chile...", op . cit., 195.

111 "La industria nacional y los establecimientos industriales fiscales", en Boletín de la Sociedad de Fomento Fabril, tomo XLVIII, Santiago, 1931, 17.

112 Arturo Alessandri Palma, Mensaje leído por S.E. el presidente de la República en la apertura de las sesiones ordinarias del Congreso Nacional, 21 de mayo de 1933, Santiago, s/1, 40-41.

113 "Asamblea de Industriales. Celebrada en Santiago de Chile los días 12, 13, 14 y 15 de Diciembre de 1920", en Boletín de la Sociedad de Fomento Fabril, tomo XXXVIII, Santiago, 1921, 69.

114 Chile. Cámara de Diputados, Boletín de las Sesiones Extraordinarias correspondiente a 1923 1924,80 .

115 Chile. Ministerio de Guerra, Memoria correspondiente a 1909, 37. 
militares en los trenes de EFE en la línea al puerto de San Antonio, lo que implicaba entregarles el control de la comunicación de la capital con la costa, ante lo cual el Consejo respondió que el manejo militar no era recomendable, sugiriendo, como compensación, las líneas angostas de la Red Central Norte de EFE para la instrucción. Frente a esta sugerencia, tanto el Ministerio de Guerra como el Ejército comunicaron que podían hacerse cargo de toda la Red Norte, a lo cual se opuso la Dirección General de EFE. Los militares insistieron y todo acabó en 1920 cuando el Ministerio de Ferrocarriles contestó que no debía continuarse con un asunto que excedía las facultades de la empresa y "que no cuenta con la aprobación del Gobierno"116.

Meses más tarde el Ministerio de Guerra volvió a la carga, para que el Regimiento de Ferrocarrileros operara la línea de Santiago a San Antonio, por "altos intereses de orden interior y exterior del país", lo que el Consejo nuevamente sometió a trámite ${ }^{117}$. En 1922, el Ministro de Ferrocarriles informó en la Cámara de Diputados que se habían presentado reparos para la entrega de esta al Ejército, lo que dejó paralizada la propuesta. En 1924, la Junta Militar determinó integrar al consejo de EFE un oficial del Ejército, para que interviniera en aspectos relacionados con la capacidad militar de los ferrocarriles, pero después de 1932 se eliminaron los consejos y la presencia militar en los organismos estatales ${ }^{118}$.

\section{UN PROYECTO A FLOTE: EL LOBBY NAVAL EN GRAN BRETAÑA DESPUÉS DE LA PRIMERA GUERRA MUNDIAL}

Los proyectos por controlar los ferrocarriles se dieron en el contexto de los intentos de golpe de Estado y de planteamientos nacionalistas, que se expresaron en el complot de los generales Armstrong y Moore en 1919, quienes plantearon una política productiva y de reforma social: "impulsar el desarrollo industrial del país, para obtener nuestra independencia económica y asegurar la defensa nacional, abasteciéndonos con nuestros propios recursos, fundándose fábricas de elementos militares y de toda clase de industrias que propicien abundante trabajo al pueblo" 119 . Pero ese intento y otros fallaron, por divergencias entre los conspiradores y porque el gobierno les restó fuerza al concentrar tropas en la frontera con Perú y Bolivia $^{120}$.

116 "Actas del Consejo Administrativo", en Boletín de los Ferrocarriles del Estado, año 8, № 1 , Santiago, 1920, 38-39; "Actas del Consejo Administrativo", en idem, año VIII, N 4, 354.

117 "Actas del Consejo Administrativo", en idem, año IX, No 10, 1.025; Cámara de Senadores, Boletín de las Sesiones Extraordinarias correspondiente a 1922, 137.

118 Boletín de los Ferrocarriles del Estado, año XIV, No 2, Santiago, 1925, 42; Ferrocarriles del Estado, Ley de administración de los Ferrocarriles del Estado. Ley 9.336 (Refunde en un solo texto las disposiciones del D.F.L. 167 de 12 de mayo de 1931 y de las leyes 7140 y 9313), Santiago, Talleres Gráficos de los Ferrocarriles del Estado, 1950, 5-10.

119 Citado en Piuzzi, op. cit., Vol. 2, 615.

120 Julio Heise González, Historia de Chile. El período parlamentario, 1861-1925. Tomo I. Fundamentos histórico-culturales del parlamentarismo chileno, Santiago, Editorial Andrés Bello, 1974, 275-276; Harold Blakemore, "Chile...", op. cit., 192. 
También debe considerarse un aspecto estrictamente militar que le restó sentido a la intervención de estos en la economía: los posibles conflictos de Chile no serían de la escala de los europeos, aspecto anotado -otra vez- por Von Kiesling, quien señaló que ninguno de los adversarios tendría grandes masas de hombres y de municiones para sostener una guerra prolongada: "a todos les falta la industria poderosa y tan necesaria para el desarrollo de su artillería pesada, como la poseen las grandes potencias europeas". Los medios modernos no tendrían mucha importancia y las operaciones se parecerían a las ocurridas en Europa Oriental y Asia Occidental, lo que haría necesario en primer lugar el desarrollo de la logística, marginalmente la movilización nacional y en menor medida una industria que le diera cierta autonomía ${ }^{121}$.

Distinta fue la situación de la Armada, que después de la guerra europea reforzó su relación con Gran Bretaña, en un sentido diametralmente opuesto al del Ejército y sectores de los ingenieros navales que planteaban establecer industrias nacionales. En 1919, mientras en el Ejército los generales Armstrong y Moore manifestaban subversivamente el desarrollo de industrias nacionales y el Estado Mayor quería tomar control de los ferrocarriles, el jefe de la misión naval de Chile en Inglaterra visitó diversos centros industriales, como Newcastle, Glasgow y Sheffield, se entrevistó con empresarios británicos que mantenían relaciones con Chile y los interesó en los recursos naturales del país. El lobby naval quería desarrollar un nicho no disputado en Chile, como era el de los astilleros y la producción de acero. Se presentaron algunos proyectos e incluso viajó a Chile un ingeniero de la firma Armstrong Whitworth \& Co., para estudiar la posibilidad de establecer una siderúrgica122. Más claro no podía ser: "si se piensa mantener las relaciones que nos unen con los industriales de Gran Bretaña, lo que conviene a los intereses de la Armada y del país en general, la Comisión Naval está llamada como antes a prestar muy buenos servicios" 123 .

El papel conservador de la Armada como freno al productivismo militar fue clave, a través de su apoyo a las juntas militares y gobiernos que desplazaron a los jóvenes oficiales de 1924, al igual como lo hizo en 1973 para darle entrada a una opción liberal.

Esas opciones estaban en más sintonía con las del resto del aparato estatal, en las que los ingenieros incrementaron su relación con los Estados Unidos. Así EFE, en 1919, estableció una oficina permanente en Nueva York, para manejar información, contratos y comprar directamente la tecnología necesaria ${ }^{124}$. Es decir, EFE y la Armada negociaban su viabilidad con las potencias triunfantes, pero parte de la oficialidad del Ejército insistía en el derrotado modelo de coordinación alemán.

121 Von Kiesling, op. cit., 104-105 y 115.

122 MMM, 1919, 814 .

123 Ibid., 820.

124 Guillermo Guajardo, "La tecnología de los Estados Unidos y la 'Americanización' de los ferrocarriles estatales de México y Chile, ca. 1880-1950”, en TST Revista de Historia de los Transportes, Servicios y Telecomunicaciones, No 9, Madrid, 2005, 110-130. 
La parte "civil" del Estado chileno definió sus vínculos tecnológicos hacia el polo de nuevas innovaciones, mientras que las instituciones armadas se aferraron a sus tradicionales vínculos europeos. En la década de 1940 se agregó un nuevo factor de dependencia internacional de las Fuerzas Armadas chilenas, a través de la Fuerza Aérea, que recibió a la primera Misión Aérea Norteamericana ${ }^{125}$.

\section{LA SUPREMACÍA TECNOCRÁTICA: LOS INGENIEROS CIVILES Y EL FRENO AL INDUSTRIALISMO MILITAR}

Las posturas políticas más moderadas, la importancia ascendente de los Estados Unidos y la continuidad estratégica con Gran Bretaña permitieron reconfigurar el instrumental tecnológico de la supremacía civil y tecnocrática que pondría fin a las intervenciones y proyectos militares.

Tal como lo hemos señalado antes, los movimientos militares culminaron con el gobierno del general Carlos Ibáñez (1927-1931), quien abrió el camino a las clases medias, diversificó la economía con la entrada de inversiones estadounidenses, inició la industrialización sustitutiva y le dio el mando de la economía a una nueva tecnocracia civil representada por los ingenieros ${ }^{126}$. Estos últimos ya tenían un papel muy claro en las decisiones estatales a través de las obras públicas y estaban escalando hacia el control de las agencias encargadas de financiar actividades productivas, comercializar y explotar recursos, dirigir los ferrocarriles y construir caminos, movilizando la capacidad de intervención del Estado ${ }^{127}$.

Ello puso en evidencia la incompatibilidad entre un manejo técnico y uno militar de los factores económicos. Un ejemplo de esas contradicciones se dio en 1928 , con el decreto para combatir la "ociosidad", que impuso el trabajo obligatorio en todas las cárceles y la detención de "vagos" por carabineros, para enviarlos a trabajar a la minería, agricultura y obras públicas. Estas medidas coercitivas, ajenas a un mercado libre de trabajo, se acompañaron de análisis que indicaban que mientras no se aplicaran en Chile los principios del sistema Taylor, todas las medidas adoptadas para levantar la productividad del trabajo serían vanas ${ }^{128}$. El Estado trataba de sintetizar las visiones de los empresarios y militares sobre el uso del trabajo, pero expresaba los dilemas de aumentar la importancia de los trabajadores industriales, desafío que estaba detrás de cualquier estrategia de expansión industrial.

A esto se debe agregar que la proximidad a un proyecto obrero e industrial nunca fue una prioridad política de las Fuerzas Armadas ni una conducta consecuente en su interior. Tales fueron los desafíos que se presentaron en los talleres

\footnotetext{
125 Alejandro Iturra, "La elección del F-16: una definición orientada por el peso de la historia", en Estudios Político Militares, No 1, Santiago, 2001, 41.

126 Domínguez, op. cit., 47-57; Ibáñez, "Los ingenieros", op. cit.

127 Palma, op . cit., 171-184; Ibáñez, "El liderazgo", op. cit., 183-216.

128 Guillermo Guajardo, "Tecnología y trabajo en Chile, 1850-1930", en Cuadernos Americanos, No 38, México, 1993, 155-179.
} 
del Apostadero Naval de Talcahuano, donde sus obreros -al igual que el resto de los trabajadores chilenos- tenían bajos salarios y malas condiciones de trabajo y vida. A partir de 1924 las demandas sociales se empezaron a radicalizar. Aprovechando una visita de Alessandri al ANT, las organizaciones obreras pidieron aumento de jornales, seguro médico, pago de salarios durante la enfermedad, estímulos para ascender y representantes obreros en la administración de los Arsenales de Marina. El movimiento militar de septiembre de 1924 había contado en la Armada con el apoyo de los oficiales ingenieros, obreros y tropa del ANT, situación que rompió las fronteras institucionales y jerárquicas y que se reflejó en las manifestaciones por el regreso de Alessandri a Chile, en enero de 1925, en el puerto de Talcahuano, donde hablaron representantes de la Federación Obrera de Chile, de los partidos Demócrata y Comunista e ingenieros de la Armada ${ }^{129}$.

En esas movilizaciones sociales y políticas, aparecieron las disputas entre los ingenieros militares y los oficiales de guerra. En 1925 los oficiales mayores, categoría que englobaba tanto a los oficiales ingenieros formados en la EIM de la Armada, como a los cirujanos y contadores, publicaron un manifiesto en que apoyaban a la "juventud militar" y denunciaban a los oficiales ejecutivos o de guerra, a cargo de los cuales estaba el comando militar de las naves, por oponerse a las reformas sociales. Esto fue considerado una amenaza, por romper la cadena de mando a cargo de los oficiales de guerra que se formaban en la Escuela Naval, quienes elaboraron un documento para la superioridad de la Armada, llamado "Memorial presentado a la Comisión dirigida por la circular confidencial $\mathrm{n}^{\circ} 1$ del 5 de noviembre de 1924 por los oficiales de guerra residentes en Talcahuano", donde plantearon que los oficiales ejecutivos debían comandar todas las actividades técnicas ocupadas por los oficiales ingenieros, en reacción a la politización y liderazgo ejercido por estos ${ }^{130}$. Ello estuvo detrás de la fusión de la EIM y la Escuela Naval.

Sin embargo, la disputa no terminó ahí y alcanzó su clímax tras la caída de Ibáñez, en 1931, cuando se volcaron hacia la izquierda las últimas intervenciones militares, con la sublevación de la escuadra, en septiembre de 1931, y con la República Socialista, en $1932^{131}$. En la Armada los oficiales graduados en la Escuela Naval cerraron filas para darle fin al protagonismo militar, con los procesos judiciales de 1932 contra los participantes en la rebelión de la escuadra y la unificación de la EIM con la Escuela Naval, logrando los oficiales de guerra imponer sus condiciones.

Todo lo anterior provocó un rápido giro en las ideas militares. En 1933 el general Carlos Sáez, ex ministro de Guerra de Ibáñez, expresó que la defensa nacional debía "amoldarse en cada momento a la capacidad económica del país",

129 Adelante, Talcahuano, 30 de junio de 1917; 17 de julio de 1917; 26 de marzo de 1924; 31 de enero de 1925.

130 Idem, 5 de mayo de 1925.

131 William Sater, "The Abortive Kronstadt: the Chilean Naval Mutiny of 1931", en Hispanic American Historical Review, Vol. 60, Duke, 1980, 239-268. 
porque el dinero era el nervio de la guerra y "sin un sólido crédito exterior disminuyen las expectativas de éxito favorable"; por lo que "es un ideal que el país esté en condiciones de bastarse a sí mismo en caso de guerra. Acercase a este ideal es una buena política, siempre que ello no comprometa los intereses generales"132. El nervio de la guerra ya no era la producción, sino el crédito externo, lo que expresaba un giro notable en sus ideas. Así, derrotada la competencia de los militares, desde la década de 1930 los planes industrialización fueron trazados por los ingenieros estatales y los empresarios ${ }^{133}$.

Finalmente debe considerarse que los planteamientos militares se hicieron cada vez más "civiles", en la medida en que querían superar su condición de fuerza armada preindustrial, pero sin recurrir a los civiles. Además, ¿qué sentido tendría mantener una industria "potencial" de guerra con compras estatales?, ¿no era mejor desarrollar un fuerte mercado interno para sostener esa industria?

\section{CONCLUSIÓN}

Conflictos, carrera de armamentos, tecnificación del personal y profesionalización acompañada de intervenciones en la política, hasta la década de 1930, definieron tanto el perfil tecnológico como las ideas y proyectos de las Fuerzas Armadas chilenas. La carrera de armamentos terrestres y navales, desde el decenio de 1880 , formó oficiales ingenieros y personal calificado, pero careció de ideas y fuerzas suficientes para definir un proyecto económico coherente que pudiera ser dirigido por los ingenieros militares. Después de 1918 fue difícil ir más allá; la Primera Guerra dio el ejemplo de que se podían coordinar recursos e industrias militares, pero una guerra tan prolongada estaba fuera de la realidad de los posibles conflictos de Chile. Los proyectos que sí lograron llevar a cabo eran los que estaban enfocados a establecer una capacidad local de astilleros y arsenales de reparaciones, producción de municiones, adaptación y reciclaje, cercana a una ordnance factory colonial, pero sin alcanzar sofisticación ni escala industrial.

Un aspecto político clave fue que los militares no establecieron vínculos con los empresarios de industrias y manufacturas, ni lograron un consenso institucional, ya que el alto mando, tanto de la Armada como del Ejército, los bloquearon. Los proyectos surgieron como manifestación del cambio tecnológico institucional y del crecimiento de las capacidades profesionales y productivas, los cuales no se gestaron desde el ambiente universitario de una élite técnica, sino en el contacto con sus armas. Desde esos ambientes se fue escalando a cuestionar el tipo de economía existente antes de la Depresión de 1929. Los oficiales ingenieros de

132 Carlos Saéz, "Política militar" [1933], en Chile. Ejército de Chile. Academia de Guerra, op. cit., 132-133.

133 Peter S. Cleaves, Bureaucratic politics and administration in Chile, Berkeley, University of California, 1974; Óscar Muñoz (edit.), Historias personales, políticas públicas (entrevistas de Margarita Serrano y Marcia Scantlebury), Santiago, Editorial Los Andes - CIEPLAN, 1993. 
barcos y maestranzas se volvieron incómodos para sus propias instituciones, al desafiar al resto de los oficiales no técnicos; además de lo cual sus acciones colisionaron con la dirección civil de la economía. Finalmente, ante los efectos económicos de la Depresión de 1929, con crisis social y fractura institucional, el alto mando y el gobierno civil desecharon los núcleos de ideas que proyectaran a los militares más allá de sus cuarteles y barcos. 